\title{
The Role of Multiscale Interaction in Tropical Cyclogenesis and Its Predictability in Near-Global Aquaplanet Cloud-Resolving Simulations ${ }^{\circ}$
}

\author{
PORNAMPAI NARENPITAK AND CHRISTOPHER S. BRETHERTON \\ Department of Atmospheric Sciences, University of Washington, Seattle, Washington \\ MARAT F. KHAIROUTDINOV \\ School of Marine and Atmospheric Sciences, Stony Brook University, State University of New York, Stony Brook, New York
}

(Manuscript received 21 January 2020, in final form 8 June 2020)

\begin{abstract}
Tropical cyclogenesis (TCG) is a multiscale process that involves interactions between large-scale circulation and small-scale convection. A near-global aquaplanet cloud-resolving model (NGAqua) with 4-km horizontal grid spacing that produces tropical cyclones (TCs) is used to investigate TCG and its predictability. This study analyzes an ensemble of three 20-day NGAqua simulations, with initial white-noise perturbations of low-level humidity. TCs develop spontaneously from the northern edge of the intertropical convergence zone (ITCZ), where large-scale flows and tropical convection provide necessary conditions for barotropic instability. Zonal bands of positive low-level absolute vorticity organize into cyclonic vortices, some of which develop into TCs. A new algorithm is developed to track the cyclonic vortices. A vortex-following framework analysis of the low-level vorticity budget shows that vertical stretching of absolute vorticity due to convective heating contributes positively to the vorticity spinup of the TCs. A case study and composite analyses suggest that sufficient humidity is key for convective development. TCG in these three NGAqua simulations undergoes the same series of interactions. The locations of cyclonic vortices are broadly predetermined by planetary-scale circulation and humidity patterns associated with ITCZ breakdown, which are predictable up to 10 days. Whether and when the cyclonic vortices become TCs depend on the somewhat more random feedback between convection and vorticity.
\end{abstract}

\section{Introduction}

Tropical cyclones (TCs) are a form of organized moist convection spanning hundreds of kilometers that cause disastrous damage from strong wind, intense precipitation, and storm surge. TCs have been studied for centuries, but forecasts of tropical cyclogenesis (TCG) remain challenging (Emanuel 2018). TCG can occur over ocean regions with warm sea surface temperature (SST), sufficient absolute (planetary plus relative) vorticity, high lower- to midtropospheric humidity, and little vertical wind shear. In these conditions, a precursor vortex can organize sustained deep convection around its core, spinning up surface winds that intensify latent

\footnotetext{
Supplemental information related to this paper is available at the Journals Online website: https://doi.org/10.1175/JAS-D-200021.s1.
}

Corresponding author: Pornampai Narenpitak, pornampai. narenpitak@noaa.gov heat fluxes that can fuel vortex intensification (Gray 1968). But not all precursor vortices amplify, and it is important to better understand the predictability of TCG.

To this end, observational data and simulations that both encompass large-scale dynamics and resolve deep convection are needed. In this study, we use a tropical-channel configuration of the System of Atmospheric Modeling (SAM) cloud-resolving model (CRM) (Khairoutdinov and Randall 2003). This near-global aquaplanet configuration, which we call NGAqua, has a 4-km horizontal grid resolution, and it can realistically simulate both tropical convection and large-scale circulations (Bretherton and Khairoutdinov 2015; Narenpitak et al. 2017). The NGAqua simulations analyzed in this paper, which have a maximum SST well north of the equator, produce TCs spontaneously from the north edge of the intertropical convergence zone (ITCZ).

Publisher's Note: This article was revised on 30 July 2020 to acknowledge a funder that was omitted from the Acknowledgments section when originally published. 
In the remainder of the introduction, we briefly summarize some studies of TCG relevant to the analyses and discussion for this paper. Because TCG involves multiscale processes, both large-scale and small-scale genesis pathways are discussed.

\section{a. Large-scale processes}

Large-scale TCG pathways emphasize the role of preexisting synoptic-scale disturbances of lower-tropospheric vorticity that are amplified by convective feedbacks. Ferreira and Schubert (1997) and Wang and Magnusdottir (2005) studied the planetary-scale patterns of humidity and vorticity associated with the ITCZ breakdown that leads to TCG. They found that the large-scale zonal flows in the east tropical Pacific Ocean and convection associated with the ITCZ provide necessary conditions for barotropic instability. Zonally elongated strips of positive low-level absolute vorticity break down and organize into cyclonically rotating clusters of storms. Other examples of large-scale disturbances that lead to TCG are the African easterly waves in the Atlantic Ocean (Tyner and Aiyyer 2012; Leppert et al. 2013) and the monsoon trough in the northwest Pacific Ocean (Ritchie and Holland 1999; Wu and Duan 2015). Connections between TCG and other equatorial waves were also analyzed by other studies such as Frank and Roundy (2006) and Schreck et al. (2012).

The cyclonic vortices associated with these tropical disturbances can intensify into TCs given additional suitable environmental conditions. For instance, small vertical wind shear in the region of instabilities helps with the formation of cyclonic vortices (Zhang and Tao 2013). High low- to midtropospheric humidity also favors tropical convection (Bretherton et al. 2004; Raymond et al. 2015; Rushley et al. 2018). A cyclonic vortex with small vertical wind shear can act as a "marsupial pouch" that helps isolate a column of high humidity conducive to TCG (Dunkerton et al. 2009; Gjorgjievska and Raymond 2014).

\section{b. Small-scale processes}

Small-scale TCG pathways focus on convective precursors such as mesoscale convective systems (MCSs), in which latent heating and midtropospheric ascent stretch preexisting low-level absolute vorticity (Houze 2010). Fine-resolution simulations in limited-area domains have shown how such convective precursors can lead to the spinup of a midlevel cyclonic vortex (MCV). For example, Chen and Frank (1993) demonstrated that sustained upper-tropospheric warming in the stratiform clouds can spin up vorticity underneath due to vertical stretching. Bister and Emanuel (1997) suggested that evaporative cooling of precipitation in the lower troposphere can spin up the vorticity aloft and lead to a
MCV formation. Kerns and Chen (2015) showed that adiabatic warming from the rear-inflow jet next to the stratiform clouds can also intensify the vorticity. As the vorticity increases, the system develops a strong closed circulation with a warm core and low surface pressure.

Bister and Emanuel (1997) discussed how surface fluxes over warm SST can destabilize the lower troposphere after a prior mesoscale convective system has cooled it by evaporation of precipitation. This may allow redevelopment of convection that stretches the lowlevel vorticity, connects it with the midtropospheric MCV left behind by the prior convective system, and leads to TCG. Bretherton et al. (2005), Davis (2015), and Muller and Romps (2018) considered TCG as a natural form of self-organization of deep convection (Nolan 2011; Wing et al. 2016) in the presence of sufficient planetary vorticity that can rapidly intensify due to surface latent heat flux feedbacks.

Since these processes require a convective-permitting resolution or finer to resolve, most coarse-resolution simulations of TCs using general circulation models cannot trace back pre-TC convective systems with strong positive vorticity anomalies. As discussed in Vecchi et al. (2019), non-convective-scale indices that rely on the environmental vorticity, vertical motion, and humidity are used instead. However, NGAqua's 4-km resolution is fine enough to permit convection that resembles MCSs; hence, pre-TC convective systems similar to those discussed above can be identified and followed. At the same time, with the horizontal domain that encompasses half of Earth's circumference, NGAqua is able to produce realistic largescale circulations that are important for TC genesis.

Therefore, in this paper, we use a three-member NGAqua ensemble to answer whether it is the largescale or the small-scale processes that are important for TCG and its predictability. In particular, we will show that it is the large-scale processes that predetermine the location and the time of developing tropical cyclones. Meanwhile, the convective processes are important for the spinup, but are more random and harder to predict.

\section{c. Organization of this paper}

The NGAqua model description and simulation setup are in section 2 . The result of zonal-time-mean circulation of NGAqua is discussed in section 3. The algorithm developed for identifying and tracking the TCs is introduced in section 4. Large-scale processes associated with the ITCZ breakdown and small-scale convective processes associated with vorticity stretching are discussed in sections 5 and 6 , respectively. The scaledependent predictability of TCG, a case study from NGAqua, and composites of multiple cyclonic vortices 

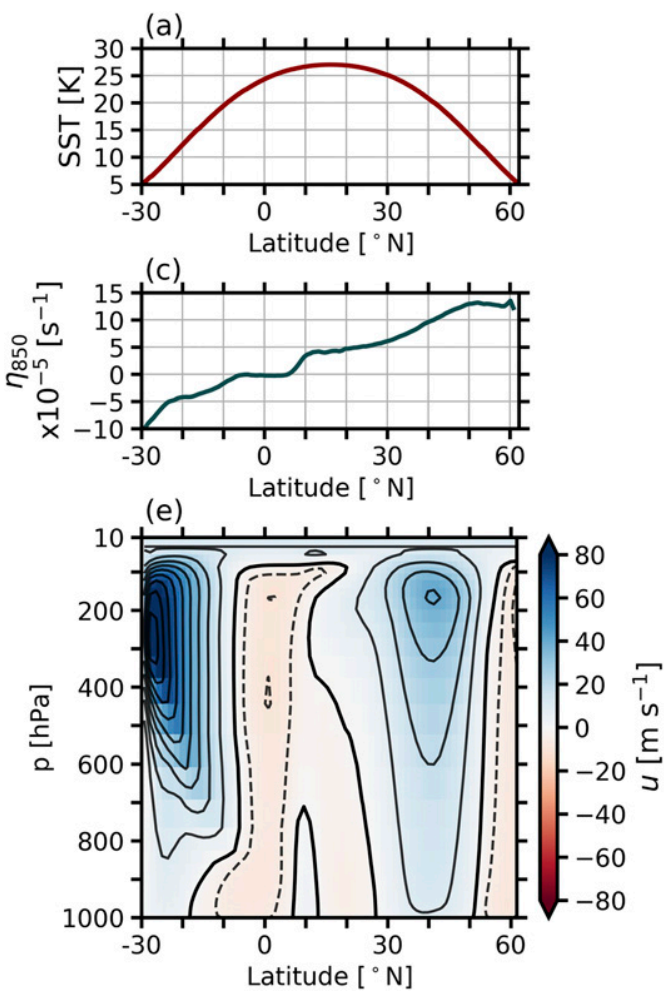

FIG. 1. Zonal-time mean from days 0 to 8 of the TC1 simulation: (a) sea surface temperature (SST), (b) surface precipitation $(\mathrm{Prec}),(\mathrm{c}) 850$-hPa absolute vorticity $\left(\eta_{850}\right)$, (d) zonal-time-mean vertical stretching $(=$ meridional convergence) of $\eta_{850}$, (e) zonal wind ( $u$ ), and (f) liquid water and ice cloud condensate $\left(q_{n}\right)$ and streamfunction. In (e), the thick solid contours indicates where $u=0 \mathrm{~m} \mathrm{~s}^{-1}$, the thin solid contours show westerly winds every $+10 \mathrm{~m} \mathrm{~s}^{-1}$, and the dashed contours show easterly winds every $-5 \mathrm{~m} \mathrm{~s}^{-1}$. In (f), thick solid lines indicate zero contours of the streamfunction, and thin solid (negative) lines show positive (negative) contours every $1000 \mathrm{~m}^{2} \mathrm{~s}^{-1}$.

are analyzed in section 7 . Finally, the discussion and conclusions are in section 8 .

\section{Model description and simulation setup}

\section{a. NGAqua tropical cyclone or "TC1" simulation}

NGAqua (Bretherton and Khairoutdinov 2015), is based on version 6.10.6 of the System of Atmospheric Modeling (SAM) cloud-resolving model (Khairoutdinov and Randall 2003). It is a tropical-channel aquaplanet CRM with 4-km horizontal Cartesian grid spacing and 32 vertical layers (12 lying below $3 \mathrm{~km}$ ), spanning a $20480 \mathrm{~km} \times 10240 \mathrm{~km}$ domain that is zonally periodic, with walls on the northern and southern boundaries. The Coriolis parameter and the SST are fixed and latitudinally dependent. Perpetual-equinox diurnal variation of insolation is applied synchronously at all longitudes. The NGAqua simulations analyzed in this paper assume a $\mathrm{CO}_{2}$ concentration of $355 \mathrm{ppm}$. NGAqua does not use any convective parameterization. It uses the original SAM single-moment bulk microphysics scheme (Khairoutdinov and Randall 2003), the Community
Atmospheric Model, version 3 (CAM3), radiation scheme (Collins et al. 2006) with interactive radiation, multidimensional positive definite advection transport algorithm (MPDATA) monotonic advection scheme (Smolarkiewicz and Grabowski 1990), and a Smagorinsky-type turbulent kinetic energy scheme. Readers are referred to Bretherton and Khairoutdinov (2015) and Narenpitak et al. (2017) for further details of NGAqua's model configuration and spinup process.

In contrast to Bretherton and Khairoutdinov (2015) and Narenpitak et al. (2017), the QOBS SST distribution of the Aqua-Planet Experiment (APE) intercomparison (Neale and Hoskins 2000), is shifted $15^{\circ} \mathrm{N}$ to a September-like "TC1" configuration shown in Fig. 1a:

$$
\operatorname{SST}(\phi)=\frac{27}{2}\left[\cos ^{2}\left(\frac{\phi-15^{\circ}}{60^{\circ}}\right)+\cos ^{4}\left(\frac{\phi-15^{\circ}}{60^{\circ}}\right)\right]\left({ }^{\circ} \mathrm{C}\right),
$$

and the latitudinal walls are similarly shifted to encompass a computational domain $31^{\circ} \mathrm{S}-61^{\circ} \mathrm{N}$. Unlike in the original equatorially symmetric NGAqua configuration, the SST maximum is collocated with sufficient planetary 
vorticity to support numerous tropical cyclones. The TC1 simulation is run for 20 days after it reaches an approximate statistical equilibrium, and the outputs are referred to as days 0 to 20 .

Instantaneous three-dimensional full-grid outputs were saved every $3 \mathrm{~h}$ for TC1, but unfortunately, they were archived only the first 8 days after the equilibrium has been reached, and even in that period there are some output gaps. Thus, the backbone of our analysis is the instantaneous hourly two-dimensional outputs that were archived. These include horizontal winds at 850 and $200 \mathrm{hPa}, 500-\mathrm{hPa}$ vertical velocities, precipitation, precipitable water, and top-of-atmosphere and surface flux components.

\section{b. Perturbed "TC2" and "TC3" simulations}

To study the predictability of TCG, two other 20-day simulations "TC2" and "TC3" were branched off the TC1 simulation after it equilibrated (day 0 ). The water vapor mixing ratio at $700 \mathrm{hPa}$ was perturbed with $0.1 \mathrm{~g} \mathrm{~kg}^{-1}$ white noise throughout the entire domain, with no changes to the other variables. For TC2 and TC3, only the hourly two-dimensional outputs were archived.

\section{Zonal-time-mean circulation in TC1 simulation}

The rest of Fig. 1 shows zonal-time-mean fields from the first 8 days of TC1, for which the three-dimensional outputs are available. The TC1 SST and tropical circulations resemble those over the tropical eastern Pacific in September (de Szoeke et al. 2007).

Figure $1 \mathrm{f}$ shows a vertical cross section of the cloud liquid and ice condensate $\left(q_{n}\right)$ and the meridional streamfunction (contours). The Hadley cell is dominated by a strong southern branch with strong crossequatorial flow. Ascent and upper-tropospheric cloud is localized in a single ITCZ between $5^{\circ}$ and $15^{\circ} \mathrm{N}$, equatorward of the maximum SST. The surface precipitation (Prec; Fig. 1b) maximizes at $8^{\circ} \mathrm{N}$, but there is also $3-5 \mathrm{~mm}$ day $^{-1}$ of mean rainfall over the warm SSTs of the northern subtropics.

Figure $1 \mathrm{c}$ shows the $850 \mathrm{hPa}$ absolute vorticity $\left(\eta_{850}\right)$, which has a strong gradient across the ITCZ separating flat "shelves" at $5^{\circ} \mathrm{S}-5^{\circ} \mathrm{N}$ and $10^{\circ}-15^{\circ} \mathrm{N}$. The northern shelf is due to southward low-level advection of planetary vorticity reinforced by zonal-time-mean vertical stretching (equal to meridional convergence) of $850-\mathrm{hPa}$ absolute vorticity (Fig. 1d) on the north edge of the ITCZ. The southern shelf is due to northward low-level advection of negative absolute vorticity. Near $15^{\circ} \mathrm{S}$, the descending branch of the Hadley circulation drives lower-tropospheric vortex compression. Since $\eta_{850}$ is negative there, this manifests as a second positive source in Fig. 1d that is not collocated with precipitation.

Figure 1e shows a vertical cross section of the zonal wind $(u)$. The low-level easterly trade winds at $15^{\circ}-25^{\circ} \mathrm{N}$ have a zonal component of up to $-10 \mathrm{~m} \mathrm{~s}^{-1}$ and very little southward component. The southeasterly trade winds at $0^{\circ}-10^{\circ} \mathrm{S}$ are slightly stronger and have a large cross-equatorial component. They recurve between $5^{\circ}$ and $10^{\circ} \mathrm{N}$ as they enter the ITCZ. Since almost all of the low-level inflow into the ITCZ is from the south, the ITCZ inherits the properties of this inflow, with lowlevel westerlies and a zonal-time-mean absolute vorticity that is close to zero.

Upper-tropospheric equatorial easterlies give way to weak westerlies north of the ITCZ that increase northward to $40 \mathrm{~m} \mathrm{~s}^{-1}$ at $40^{\circ} \mathrm{N}$. These westerlies and the associated vertical wind shear are important to the track and evolution of mature TCs. A strong subtropical jet in the Southern Hemisphere is pressed against the southern boundary of the domain, but this is far removed from the region of simulated TCG, which is on the northern edge of the ITCZ.

\section{TC identification and tracking}

We developed an algorithm for tracking the cyclonic vortices and TCs in NGAqua. It looks for grid cells that have $850-\mathrm{hPa}$ relative vorticity above $3 \times 10^{-5} \mathrm{~s}^{-1}$ and SST warmer than $25^{\circ} \mathrm{C}$, which is between $0^{\circ}$ and $30^{\circ} \mathrm{N}$. This presupposes that a positive anomaly of low-level vorticity starts a feedback for spinning up TCs in NGAqua, which is consistent with previous studies as discussed in sections $1 \mathrm{a}$ and $1 \mathrm{~b}$. An algorithm called density-based spatial clustering of applications with noise (DBSCAN) (Ester et al. 1996) is used to locate the vorticity clusters, of which the centers have minimum surface pressure (PSFC) or highest low-level absolute vorticity. DBSCAN is also used to regroup the centers of the vortices into tracks of wave disturbances, as shown in Fig. 2. The waves are considered TCs when the PSFC deepens below $980 \mathrm{hPa}$. The details of the algorithm are described in the appendix.

Figure 2a shows a Hovmöller diagram of TCs and cyclonic vortices in the TC1 simulation. The "developing waves," cyclonic vortices that develop into TCs, are shown in navy and pink; the colors distinguish when the minimum PSFC reaches $980 \mathrm{hPa}$. Other cyclonic vortices, which we call "nondeveloping waves," are shown in light blue. The light pink tracks show the TCs or cyclonic vortices that have fully developed by day 0 and are weakening after that. Among the three NGAquaensemble members, four waves W1D-W4D (D for developing) develop into TCs, four waves W1A-W4A 

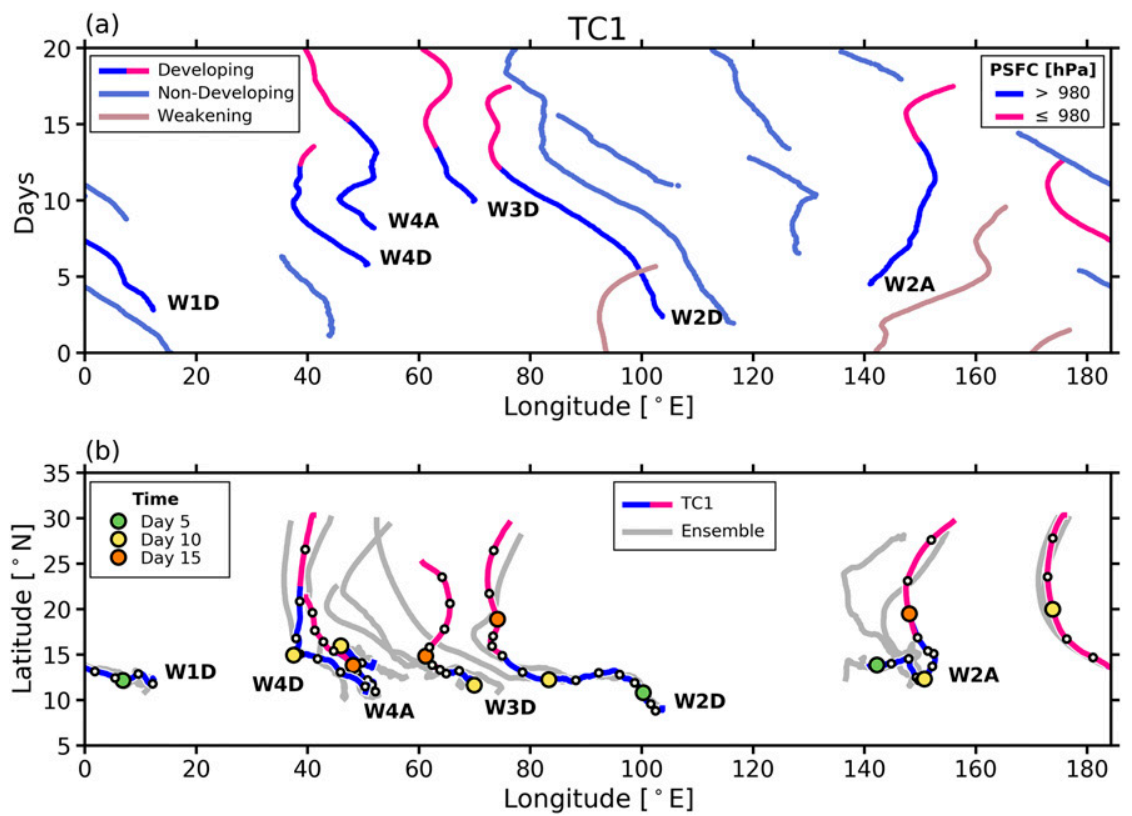

FIG. 2. (a) Hovmöller diagram of longitudes of TCs and cyclonic vortices from TC1. Vortices whose minimum surface pressure (PSFC) deepen below $980 \mathrm{hPa}$ are considered "developing waves" and are labeled as discussed in the text. They are shown in navy when PSFC $>980 \mathrm{hPa}$ and pink when PSFC $\leq 980 \mathrm{hPa}$. "Nondeveloping waves" that remain as cyclonic vortices are shown in light blue. TCs or cyclonic vortices that are weakening after day 0 are shown in light pink. (b) Tracks of the developing waves from TC1 (navy and pink) and corresponding tracks from TC2 and TC3 (gray). Small black circles on the TC1 tracks indicate the first hour of each day, and the green, yellow, and orange filled circles mark days 5, 10, and 15 , respectively.

(A for ambiguous) develop in some members only, nine waves $\mathrm{W} 1 \mathrm{~N}-\mathrm{W} 9 \mathrm{~N}$ are nondeveloping in all members, and finally three waves W1T-W3T are weakening TCs or vortices.

Figure $2 \mathrm{~b}$ shows the tracks of the six developing waves in TC1 (W1D-W4D, W2A, and W4A) using the same navy-pink intensity indicator. The black-and-white circles indicate the locations of the vortices at the first hour of each day; while the green, yellow, and orange circles indicate the first hours of days 5,10 , and 15 , respectively. Most of these waves, except for W2A, initially propagate northwestward before they recurve when the PSFC deepens; these cyclonic vortices can be regarded as easterly waves. Tracks of these six waves in TC2 and TC3 are shown in gray. The tracks diverge noticeably after day 10 . The three NGAqua ensemble members will be compared further in section 7 .

\section{The role of large-scale processes on TCG}

\section{a. Large-scale environment of a TC}

Figure 3a shows a snapshot of cloud fraction (CLD) from day 4 of TC1, when there is a mature TC with an obvious eye at $25^{\circ} \mathrm{N}, 95^{\circ} \mathrm{E}$. Figures $3 \mathrm{~b}$ and $3 \mathrm{c}$ show precipitable water (PW) and $\eta_{850}$ in the red box of Fig. $3 \mathrm{a}$.
The ITCZ is evident in Fig. 3b as a zonal band of high PW between $0^{\circ}$ and $10^{\circ} \mathrm{N}$. Low-level winds have drawn moist air from the ITCZ and wrapped it around the TC. Since the absolute vorticity is a noisy field in convectively active regions, the plotted $\eta_{850}$ is averaged to a $40-\mathrm{km}$ grid spacing. Yellow shades in the ITCZ reflect cross-equatorial flow carrying negative-vorticity air from the Southern Hemisphere. On the northern edge of the ITCZ, $\eta_{850}$ is positive (Fig. 3c). This vorticity gradient can be traced along the northwest edge of the moist tongue leading from the ITCZ into the TC. Two newly developed cyclonic vortices are visible southeast of the mature TC, but they are not apparent in the PW field at this early stage in their evolution.

\section{b. Vorticity filaments and formation of the cyclonic vortices}

Video S1 in the online supplemental material shows animations of PW and $\eta_{850}$ from TC1 simulation from day 0 to day 20. Similar snapshots of $\eta_{850}$ between $0^{\circ}$ and $30^{\circ} \mathrm{N}$ are shown in Fig. 4, overlaid by contours of zero zonal wind shear between 200 and $850 \mathrm{hPa}\left(u_{200}-u_{850}\right.$ or wind shear for short). The developing waves are shown as circles and the nondeveloping waves as hexagons. The animations and the snapshots show that the 
(a)

Day 4

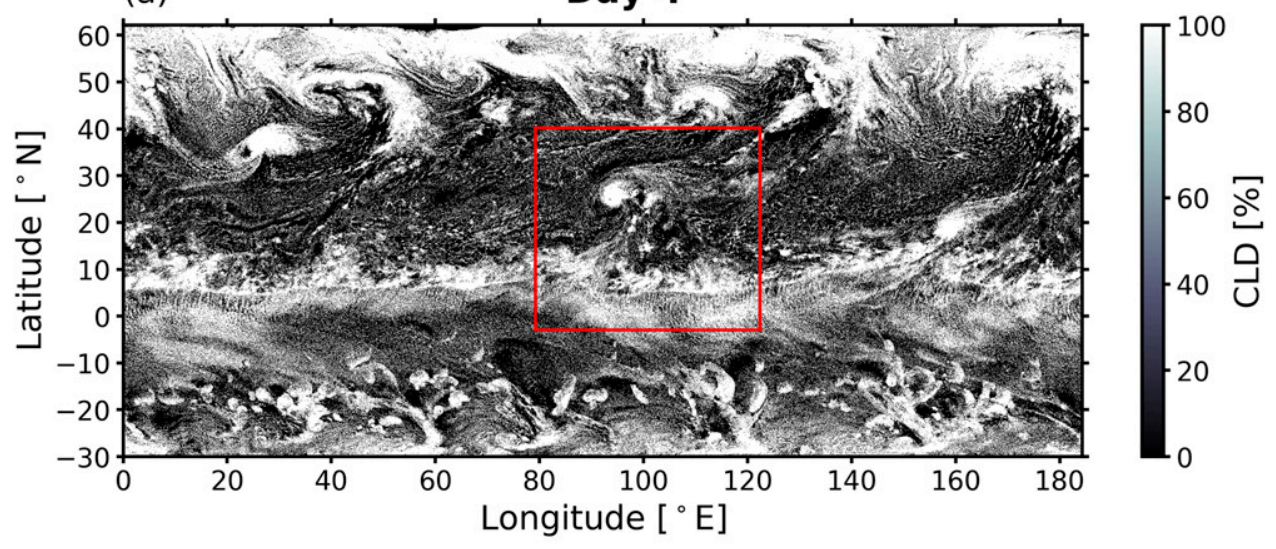

(b)

(c)
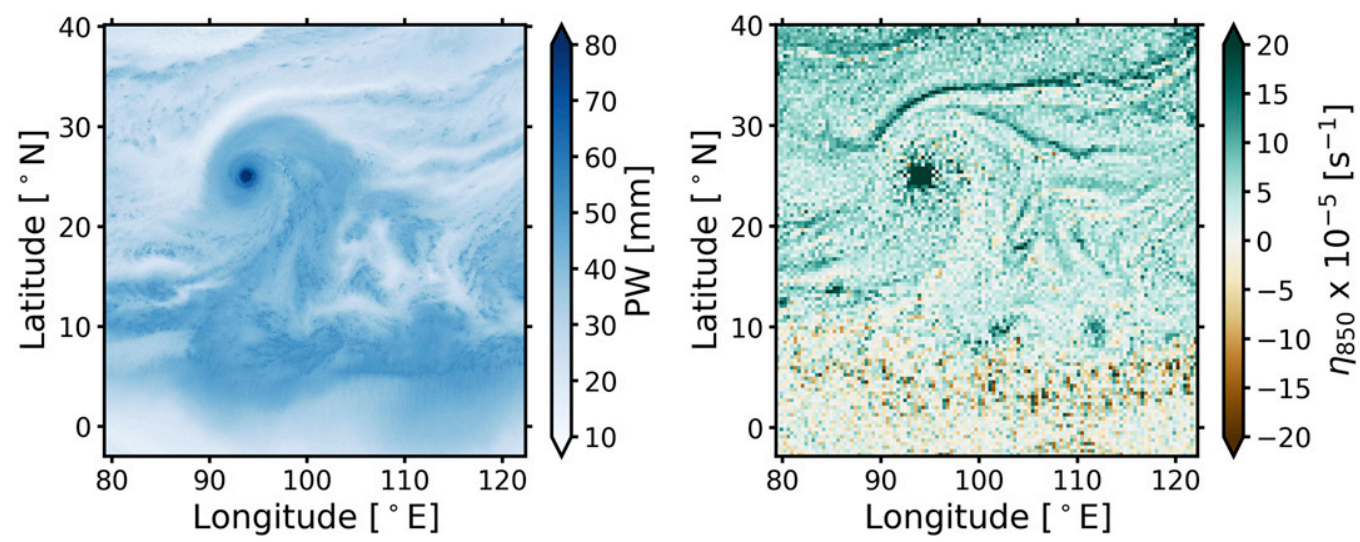

FIG. 3. (a) A snapshot of the cloud fraction (CLD) at day 4 of the TC1 simulation, showing a well-developed TC at $25^{\circ} \mathrm{N}, 95^{\circ} \mathrm{E}$, north of the intertropical convergence zone (ITCZ). (b),(c) Precipitable water (PW) and $\eta_{850}$, respectively, within the red box of (a). In (c), two new cyclonic vortices forming on the northern edge of the ITCZ can be seen to the southeast of the TC.

cyclonic vortices, regardless of whether they develop into TCs or not, spontaneously form between $10^{\circ}$ and $15^{\circ} \mathrm{N}$ from "vorticity filaments," zonal bands of positive low-level absolute vorticity found at the northern edge of the ITCZ, where the large-scale flow is favorable for lower-tropospheric barotropic instability (Ferreira and Schubert 1997; Wang and Magnusdottir 2005) and the wind shear is close to zero. Vertical stretching of lowlevel absolute vorticity, which requires strong deep convection, is needed to intensify the vortices into TCs. With weak vertical wind shear, the organized cyclonic vortices are more likely to align vertically and their moisture is better protected from infiltration of dry air that inhibits further convection (Dunkerton et al. 2009).

For example, at day 2.5 there is a vorticity filament located between $10^{\circ}$ and $30^{\circ} \mathrm{E}$ and between $10^{\circ}$ and $15^{\circ} \mathrm{N}$. By day 4.0, the zonally elongated band axisymmetrizes into a broad cyclonic vortex (red circle) that we call W1D. The vortex intensifies at day 5.5 and becomes a
TC by day 7.0, as discussed further in section $6 \mathrm{~b}$. Similarly, between $120^{\circ}$ and $160^{\circ} \mathrm{E}$ and between $10^{\circ}$ and $20^{\circ} \mathrm{N}$, there is evidence of another vorticity filament organizing into a cyclonic vortex at day 5.5 (purple circle). This vortex, W2A, will be discussed further in section $7 \mathrm{~b}$. It becomes a TC in the TC1 and TC3 simulations but not in TC2.

\section{The role of small-scale processes on TCG}

Given a preexisting cyclonic vortex organizing from a vorticity filament, can we show that convectively induced vortex stretching is the primary small-scale mechanisms that intensifies the vorticity and lead to TCG?

\section{a. Vorticity equation in a vortex-following framework}

We consider the vertical vorticity budget in a vortexrelative framework, then we apply it to the tracks in 

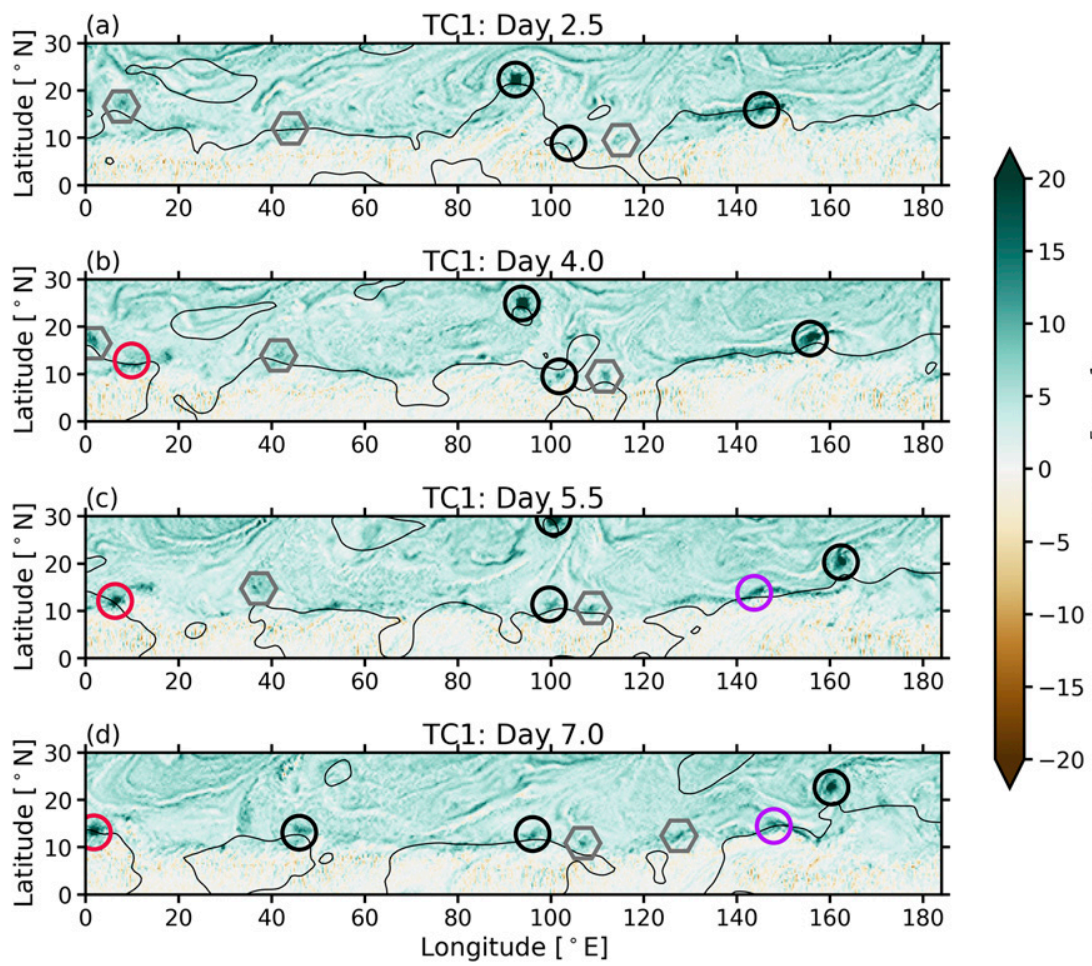

FIG. 4. Snapshots of $\eta_{850}$ between $0^{\circ}$ and $30^{\circ} \mathrm{N}$ showing vortex evolution in the TC1 simulation at (a) day 2.5, (b) day 4.0, (c) day 5.5, and (d) day 7.0. The circles highlight the developing waves; the hexagons highlight the nondeveloping waves. The thin black lines in each panel indicate where the zonal wind shear between 200 and $850 \mathrm{hPa}$ is zero. The red and purple circles highlight W1D and W2A, the developing waves discussed in Figs. 5, 6, and 10, respectively.

NGAqua. We first derive a flux form of the vorticity equation from Eq. (4.2) of Haynes and McIntyre (1987) and Eq. (3) of Raymond and Carrillo (2011). This form is advantageous since it can be exactly horizontally averaged to enable inference about vorticity sources on length scales larger than the 4-km grid.

Let $\mathbf{u}=u \mathbf{i}+v \mathbf{j}+w \mathbf{k}$ be the three-dimensional relative velocity vector, $\boldsymbol{\Omega}$ be Earth's angular velocity, and $f=$ $\mathbf{k} \cdot 2 \boldsymbol{\Omega}$ be the planetary vorticity. Then

$$
\boldsymbol{\omega}=\nabla \times \mathbf{u}=\left(\frac{\partial w}{\partial y}-\frac{\partial v}{\partial z}\right) \mathbf{i}+\left(\frac{\partial u}{\partial z}-\frac{\partial w}{\partial x}\right) \mathbf{j}+\left(\frac{\partial v}{\partial x}-\frac{\partial u}{\partial y}\right) \mathbf{k}
$$

is the relative vorticity vector, and $\boldsymbol{\omega}_{a}=\boldsymbol{\omega}+2 \boldsymbol{\Omega}$ is the absolute vorticity vector. Also let $\rho$ be the air density, $p$ be the pressure, and $\mathbf{F}$ be friction. The threedimensional vorticity equation can be written:

$$
\frac{\partial \boldsymbol{\omega}_{a}}{\partial t}=-\nabla \times\left(\boldsymbol{\omega}_{a} \times \mathbf{u}\right)+\rho^{-2}(\nabla \rho \times \nabla p)+\nabla \times \mathbf{F} .
$$

The first term on the right-hand side of Eq. (1) is the advective vorticity source, combining the effects of vertical stretching, horizontal advection, vertical advection, and tilting on $\boldsymbol{\omega}_{a}$. The second and third terms are $\boldsymbol{\omega}_{a}$ tendencies due to baroclinicity and friction, respectively.

Let $\eta=\mathbf{k} \cdot \boldsymbol{\omega}_{a}$ be the vertical component of absolute vorticity. Let the subscript $h$ denote the horizontal components of a vector, such that $\boldsymbol{\omega}_{a h}=\boldsymbol{\omega}_{a x} \mathbf{i}+\boldsymbol{\omega}_{a y} \mathbf{j}$ and $\mathbf{u}_{h}=u \mathbf{i}+v \mathbf{j}$ are the horizontal absolute vorticity and wind, respectively. A flux form of the tendency equation for the vertical component of the absolute vorticity valid in the free troposphere can be derived from Eq. (1):

$$
\begin{aligned}
\frac{\partial \eta}{\partial t} & \approx-\frac{\partial}{\partial x}(\eta u)-\frac{\partial}{\partial y}(\eta v)+\frac{\partial}{\partial x}\left(\omega_{a x} w\right)+\frac{\partial}{\partial y}\left(\omega_{a y} w\right) \\
& =\underbrace{-\nabla_{h} \cdot\left(\eta \mathbf{u}_{h}\right)}_{\text {Generalized Stretching }}+\underbrace{\nabla_{h} \cdot\left(w \boldsymbol{\omega}_{a h}\right)}_{\text {Generalized Tilting }} .
\end{aligned}
$$

The vertical components of the baroclinicity and friction terms have been neglected since they are small in the free troposphere, where we will apply this equation. On the right-hand side, $-\nabla_{h} \cdot\left(\eta \mathbf{u}_{h}\right)$ is the horizontal convergence of the absolute vertical vorticity flux, and $\nabla_{h} \cdot\left(w \omega_{a h}\right)$ is the horizontal divergence of absolute horizontal vorticity flux. The first term combines the physical vertical stretching and horizontal advection of 

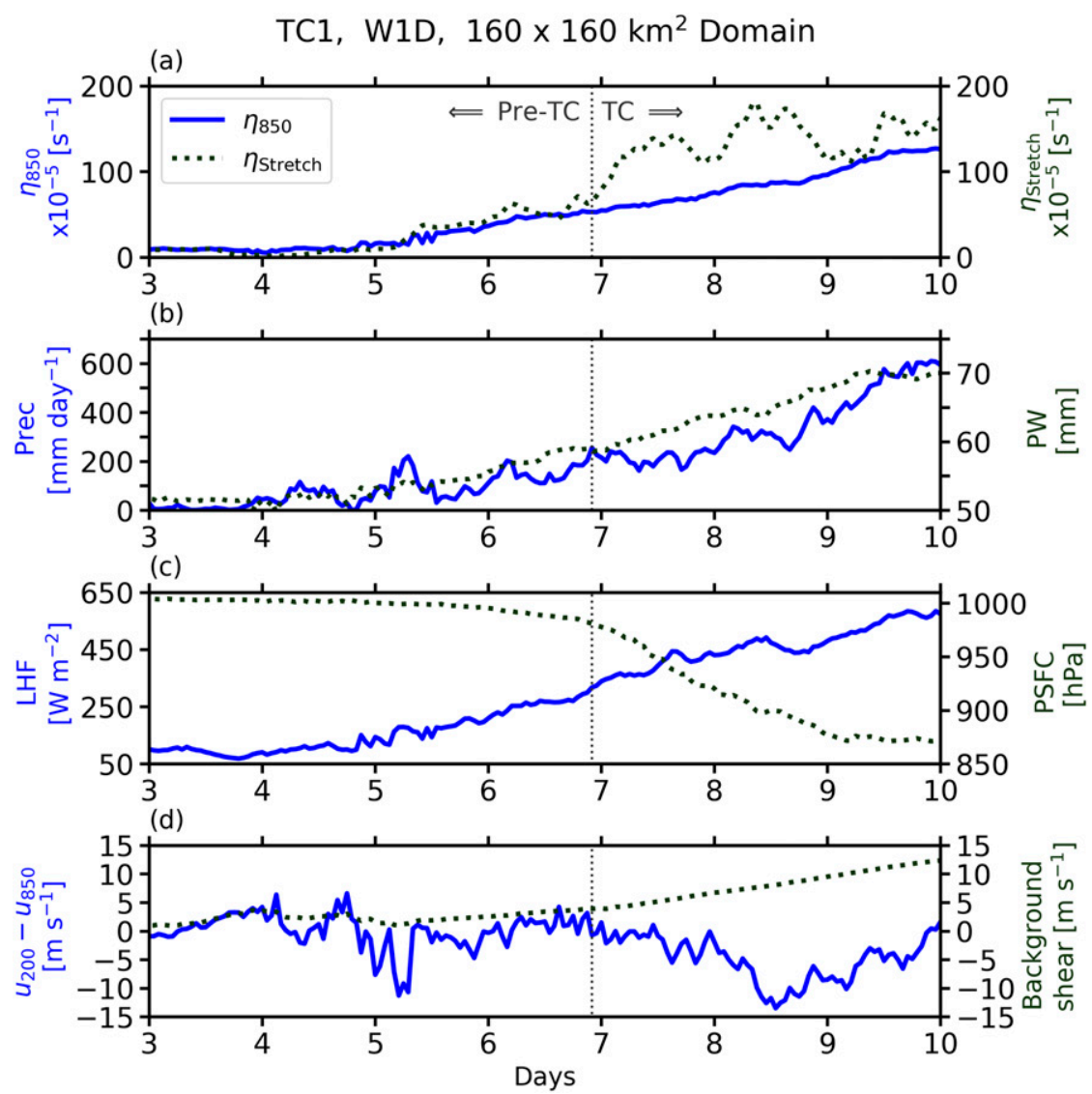

FIG. 5. Time series of various fields averaged within a $160 \times 160 \mathrm{~km}^{2}$ block of the first developing wave or W1D of TC1 simulation: (a) $\eta_{850}$ (blue) and absolute vorticity accumulated from the generalized stretching tendency $\left(\eta_{\text {Stretch }}\right.$, dark green dotted line), (b) Prec (blue) and PW (dark green), (c) surface latent heat flux (LHF, blue), and minimum surface pressure (PSFC, dark green), and (d) zonal wind shear between 200 and $850 \mathrm{hPa}\left(u_{200}-u_{850}\right)$ following the vortex (blue) and background shear at the latitude of the vortex center (dark green). The vertical dotted lines indicate the time when PSFC reaches $980 \mathrm{hPa}$ and the cyclonic vortex becomes a tropical cyclone.

$\eta$ together, while the other term combines the physical tilting and vertical advection of $\eta$. We refer to them as "generalized stretching" and "generalized tilting," respectively. In a vortex-following framework, a vortexrelative horizontal velocity is used, so Eq. (2) becomes

$$
\begin{aligned}
\frac{\partial \eta}{\partial t} & =-\nabla_{h} \cdot\left[\eta\left(\mathbf{u}_{h}-\mathbf{U}_{c}\right)\right]+\nabla_{h} \cdot\left(w \boldsymbol{\omega}_{a h}\right) \\
& =\left.\frac{\partial \eta}{\partial t}\right|_{\text {Stretch }}+\left.\frac{\partial \eta}{\partial t}\right|_{\text {Tilt }},
\end{aligned}
$$

where $\mathbf{U}_{c}$ is the horizontal velocity of the cyclonic vortex. Conveniently, the generalized stretching can be computed purely using the horizontal velocity field at that level. For all of our simulations TC1-TC3, the 850-hPa horizontal velocity was stored hourly. The generalized tilting requires the full three-dimensional velocity field to calculate the horizontal vorticity components; this was only archived three-hourly for the first eight days of TC1. Thus, with the available model outputs, we can compute generalized stretching more accurately and during much more of our simulations than generalized tilting, so our main use of the vertical vorticity budget is to compare the full $850-\mathrm{hPa}$ vorticity tendency with its tendency due to generalized stretching alone.

In particular, we compare time series of the $850-\mathrm{hPa}$ vorticity $\eta_{850}(t)$ with its accumulated stretching tendency $\eta_{\text {Stretch }}(t)$. This allows us to relate the sources (and sinks) of absolute vorticity to a term that can be easily computed given the archived 2D outputs, which include zonal and meridional wind speeds at $850 \mathrm{hPa}$ but not the vertical wind at $850 \mathrm{hPa}$. To ensure that there is a closure in the vorticity budget during the spinup period, we have picked a few $160 \times 160 \mathrm{~km}^{2}$ blocks following a developing TC where the 3D outputs are available, and 

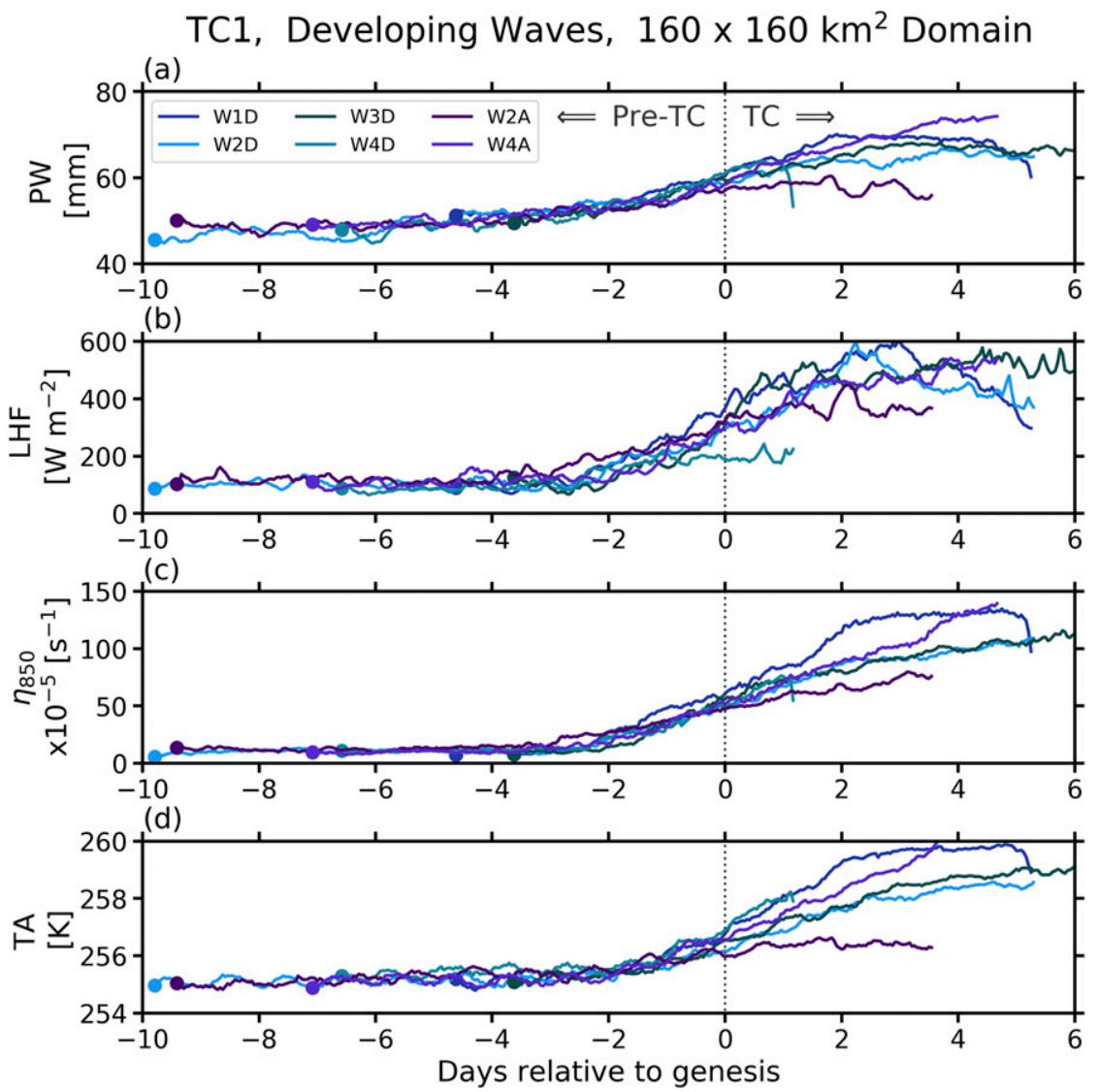

FIG. 6. Time series of (a) PW, (b) LHF, (c) $\eta_{850}$, and (d) column-averaged temperature (TA) following the six developing waves from $\mathrm{TC} 1$ simulation. The time series are plotted relative to the time of genesis when PSFC reaches $980 \mathrm{hPa}$, which is indicated by the vertical dotted lines.

computed each term in Eq. (1). The budget closes fairly well. From now on, we focus on the terms that can be computed using the variables from the archived 2D outputs, which are $\eta_{850}(t)$ and $\eta_{\text {Stretch }}(t)$.

To avoid an artificial plotting offset, $\eta_{\text {Stretch }}$ is initialized to $\eta_{850}$ at the time the vortex is first detected. If these two time series track each other, generalized stretching must be the dominant vorticity source. Before TCG, the vortex tends to move with the lowertropospheric winds, so generalized stretching in the lower to mid troposphere is due mainly to physical vertical stretching rather than vortex-relative horizontal advection.

\section{b. Vertical stretching of absolute vorticity}

Figure 5 shows the hourly time series of $\eta_{850}$ and $\eta_{\text {Stretch }}$ (Fig. 5a), Prec and PW (Fig. 5b), latent heat flux (LHF) and PSFC (Fig. 5c), and wind shear (Fig. 5d) averaged over a $160 \times 160 \mathrm{~km}^{2}$ domain following a developing TC called W1D, from the TC1 simulation. Figure $5 \mathrm{~d}$ also shows the time series of background wind shear, which is the zonal-mean wind shear at the corresponding latitudes of the vortex center. The vertical dotted line indicates the genesis time when W1D becomes a TC, in other words, when its minimum PSFC reaches $980 \mathrm{hPa}$. In general, $\eta_{850}$ and $\eta_{\text {Stretch }}$ correlate well with each other during the pre-TC stage (Fig. 5a). Starting on day 4 , the vorticity increases during periods of stronger precipitation (Fig. 5b), suggesting that convection helps stretch the atmospheric column and increase the low-level absolute vorticity. As the vortex spins up, PW and surface LHF also increase, while the wind shear remains small. After day $7, \eta_{850}$ and $\eta_{\text {Stretch }}$ no longer correlate as well. There is a systematic sink of $\eta_{850}$ from generalized tilting due to upward advection of strong positive vorticity out of the lower troposphere by cumulus convection (not shown).

Figure 6 shows time series of PW (Fig. 6a), surface LHF (Fig. 6b), $\eta_{850}$ (Fig. 6c), and column-averaged temperature (TA) (Fig. 6d) averaged over a $160 \times$ $160 \mathrm{~km}^{2}$ domain following the six developing waves found in the TC1 simulation and shown in Fig. 2. The initial 


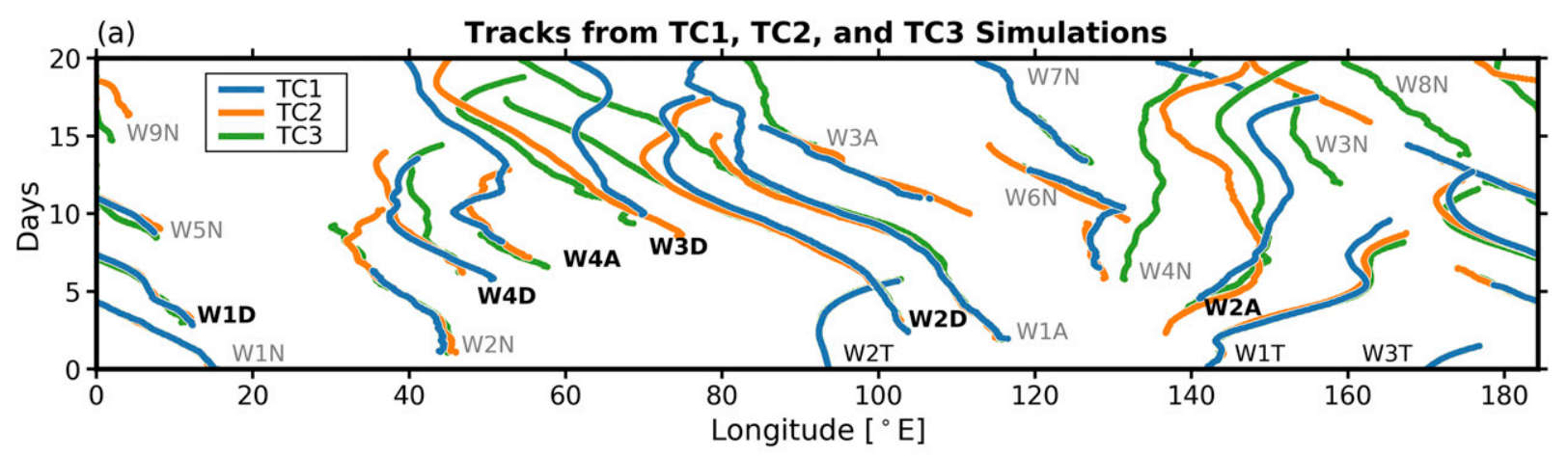

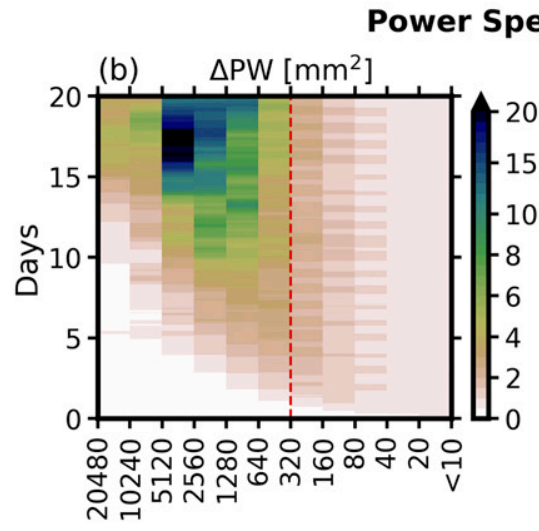

Zonal Wavelength [km]

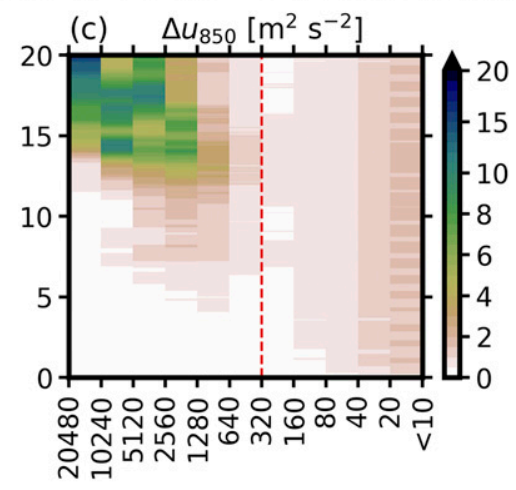

Zonal Wavelength $[\mathrm{km}]$

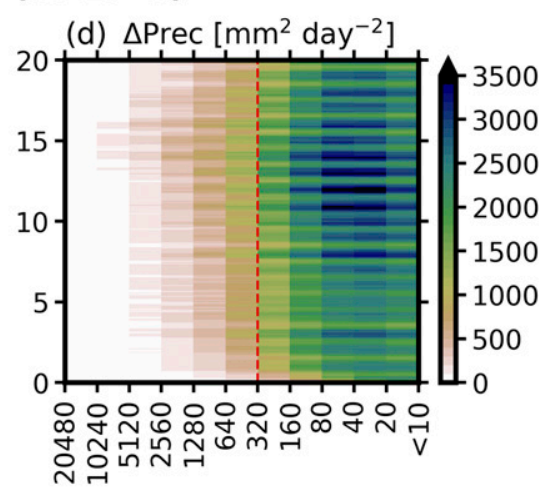

Zonal Wavelength [km]

FIG. 7. (a) Hovmöller diagram of the easterly wave and TC tracks from TC1, TC2, and TC3 simulations. Easterly waves that become TCs in the TC1 simulation (Fig. 2a) are labeled in boldface; the waves that remain as cyclonic vortices are labeled in gray. (b)-(d) Octave power spectra of TC2-TC1 and TC3-TC1 perturbations of $\mathrm{PW}, u_{850}$, and precipitation, respectively, averaged between $10^{\circ}$ and $15^{\circ} \mathrm{N}$. Red dashed lines represent the $320-\mathrm{km}$ zonal wavelength, indicative of variability across $160 \times 160 \mathrm{~km}^{2}$ blocks.

cyclonic vortices can be tracked 3-10 days prior to genesis. When plotted relative to the genesis time, the time series show a highly consistent evolution. There is an initial period in which $\eta_{850}$ stays roughly constant. The PW starts near $50 \mathrm{~mm} \mathrm{3-4}$ days prior to genesis and steadily rises to $55-60 \mathrm{~mm}$ at genesis. During this gradual PW increase, convection organizes around the vortices but is not tightly clustered around the vortex centers. Approximately 2 days prior to genesis, $\eta_{850}$ starts to rise, a warm core starts to develop (as indicated by the rising TA), and surface LHF increases as the surface winds spin up. During this phase, convection is more tightly organized around the vortex so the convection more rapidly intensifies the vortex via vortex stretching, increasing $\eta_{850}$ by approximately $40 \times 10^{-5} \mathrm{~s}^{-1}$ in the 2 days prior to genesis.

\section{The predictability of tropical cyclogenesis}

The TC2 and TC 3 simulations are perturbed at time zero from TC1 by small white noise humidity perturbations of amplitude $0.1 \mathrm{~g} \mathrm{~kg}^{-1}$ at all grid points in the
NGAqua domain at a single model level near $3 \mathrm{~km}$. Figure 7a shows a Hovmöller diagram of cyclone tracks from the three simulations. The tracks are similar up to approximately 10 days. When a TC develops before day 10 in the TC1 simulation, it will also develop at almost the same place and time in the other simulations. After day 10, the simulations diverge and TCs develop at somewhat different places and times. Video S2 shows this behavior with an animation of hourly snapshots from day 0 to day 20 of $\eta_{850}$ in the tropics of the three simulations.

\section{a. Scale-dependent predictability}

The rest of Fig. 7 shows Fourier power spectra of TC2-TC1 and TC3-TC1 perturbations of PW, $u_{850}$, and precipitation. For each hour, the TC2-TC1 and TC3TC1 spectra are computed separately and then averaged. They are analyzed similarly to Bretherton and Khairoutdinov (2015). Each zonal Fourier wavenumber $k$ corresponds to a zonal wavelength $\lambda_{x}=L_{x} / k$, where $L_{x}=20480 \mathrm{~km}$ is NGAqua's zonal domain width. The smallest wavenumber $k=1$ corresponds to $\lambda_{x}=L_{x}$, 

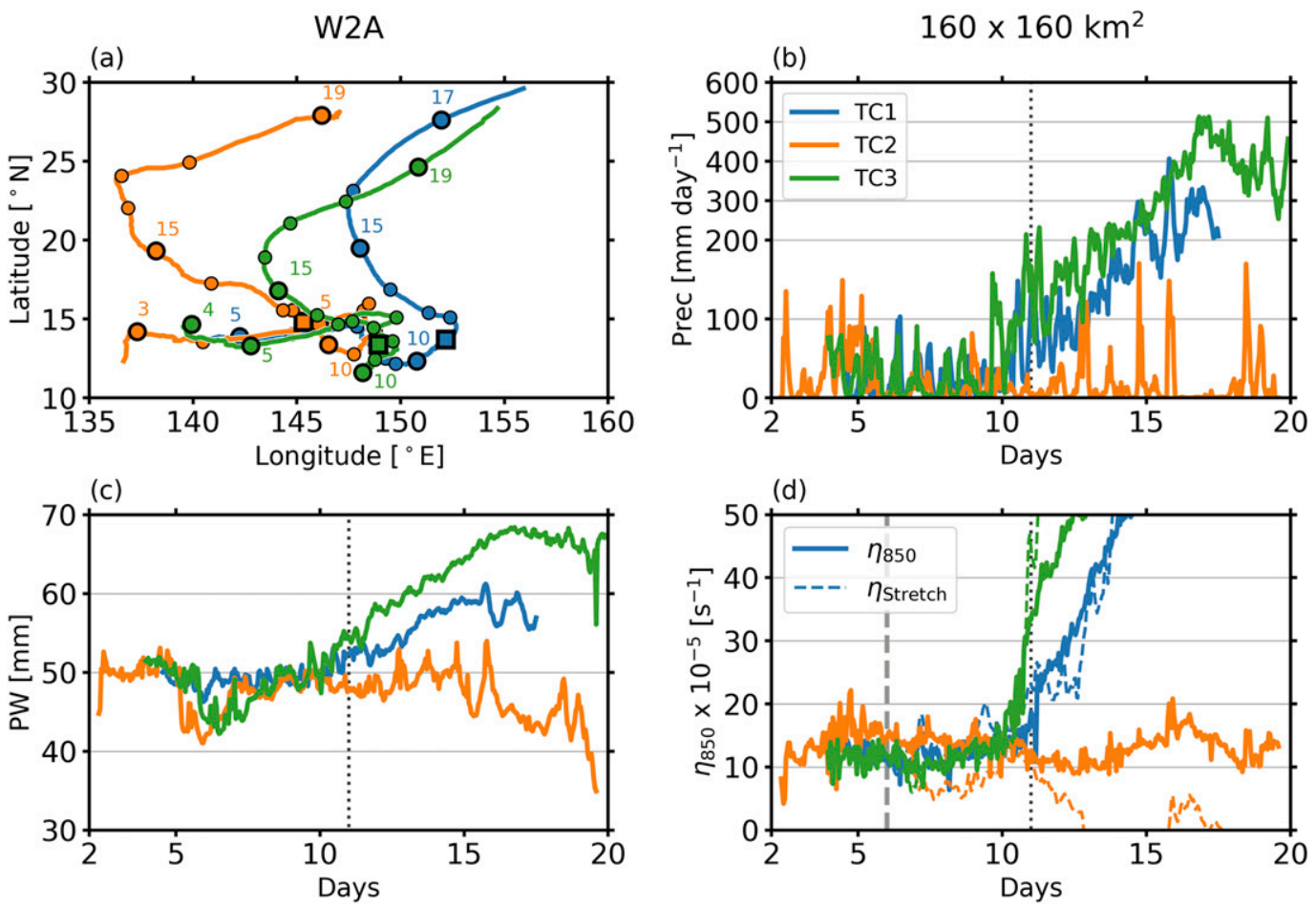

FIG. 8. Tracks and time series of W2A averaged within a $160 \times 160 \mathrm{~km}^{2}$ block from TC1, TC2, and TC3. (a) Tracks of wave W2A: The circles show the vortex centers at the first hour of each day. The squares indicate day 11, approximately when the vortices in TC1 and TC3 become TCs. (b)-(d) Time series of Prec, PW, and $\eta_{850}$, respectively. The vertical dotted lines indicate the first hour of day 11 . In (d), the dashed lines are the vorticity accumulated due to generalized stretching at $850 \mathrm{hPa}$ or $\eta_{\text {Stretch }}$, starting at day 6 , indicated by a vertical dashed line.

while $k=2560$ corresponds to the shortest zonal wavelength resolvable by the horizontal grid, $\lambda_{x}=$ $2 \Delta x=8 \mathrm{~km}$. We sum the power spectra across "wavenumber octaves" $\left(k_{p}\right)$. Each octave corresponds to the doubling of wavenumber: $2^{p-1} \leq k_{p}<2^{p}$, where $p=1,2$, $3, \ldots, 12$, except for the final octave that includes up to $k=2560$. The power spectra are averaged between $10^{\circ}$ and $15^{\circ} \mathrm{N}$, where the pre-TC vortices form.

Since the initial conditions are perturbed with whitenoise low-level humidity, the PW perturbation is initially white. It grows upscale as expected. Small-scale perturbation PW variance $\left(\lambda_{x}<80 \mathrm{~km}\right)$ saturates in the first few hours of the simulations, i.e., reaching a certain value and no longer increasing. Large-scale PW perturbations $\left(\lambda_{x}>640 \mathrm{~km}\right)$ develop more variance and take over 15 days to saturate. Large-scale perturbation $u_{850}$ variance is still modest at 10 days, suggesting that the large-scale winds help maintain predictability of TCG through this time. Finally, the precipitation perturbation variance is mostly at small scales $\left(\lambda_{x}<\right.$ $320 \mathrm{~km}$ ) and saturates in the first few hours of the simulations. This suggests that the space-time structure of convection occurring within a $160 \times 160 \mathrm{~km}^{2}$ block quickly decorrelates between the three simulations and is not an intrinsic source of predictability.

\section{b. Case study: Wave W2A}

Wave $\mathrm{W} 2 \mathrm{~A}$ is an example of a system that organizes as the large-scale winds start to decorrelate between the three simulations. It spins up into a TC on day 11 in two out of three simulations. Figure 8 a shows the tracks of W2A for the three ensemble members. In all three cases, the cyclonic vortex axisymmetrizes from the same vorticity filament that connects W1T to the ITCZ (purple circles in Figs. 4b and 4c) and propagates northeastward between days 4 and 9 along the northern edge of the ITCZ. In TC2, the vortex propagates faster than those in TC1 and TC3 simulations and does not become a TC. This is because of a strong vertical wind shear that allows dry-air intrusion into the initial vortex, as will be discussed below and in section $7 \mathrm{~b}$.

The rest of Fig. 8 shows time series of Prec, PW, and $\eta_{850}$, averaged within a $160 \times 160 \mathrm{~km}^{2}$ box following W2A. The time series diverge significantly after day 10 . The TC becomes stronger and larger in TC 3 than that in $\mathrm{TC} 1$, because higher $\mathrm{PW}$ around the vortex core in 

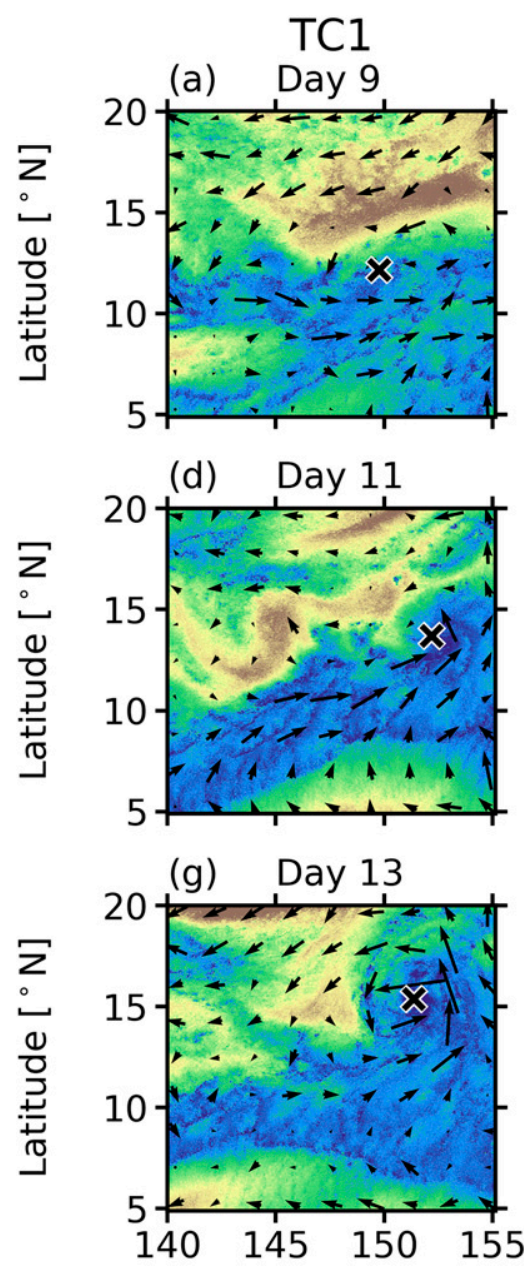

Longitude $\left[{ }^{\circ} \mathrm{E}\right]$
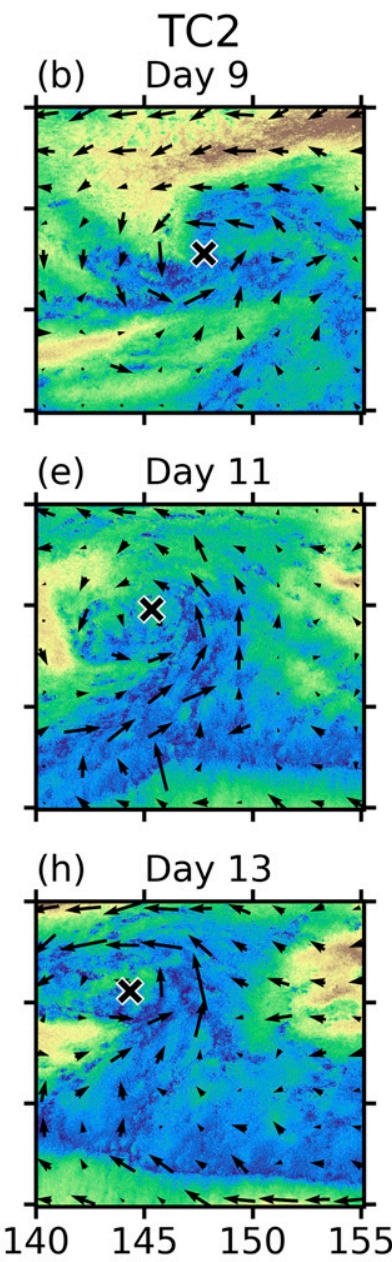

Longitude $\left[{ }^{\circ} \mathrm{E}\right]$
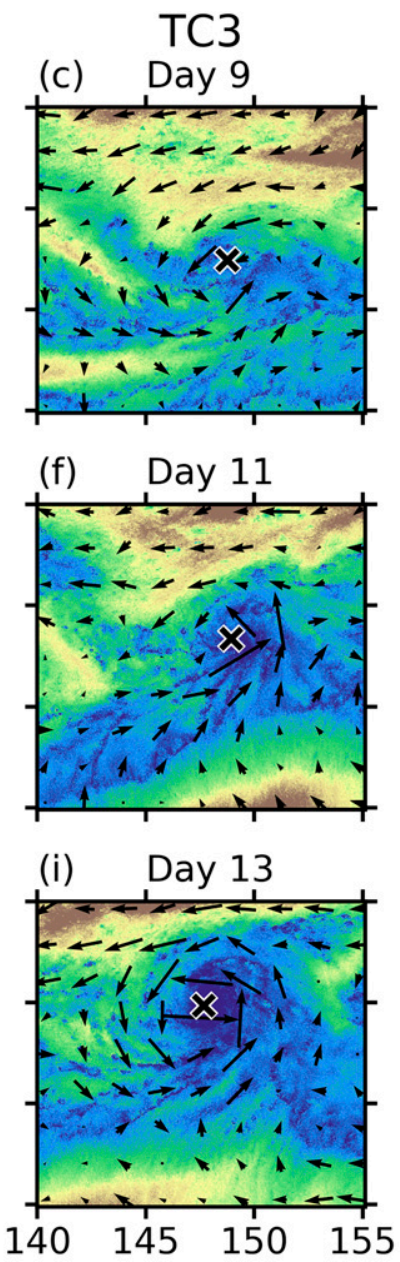

Longitude $\left[{ }^{\circ} \mathrm{E}\right]$

FIG. 9. Large-scale snapshots of PW around W2A at (a)-(c) day 9, (d)-(f) 11, and (g)-(i) 13 from (left) TC1, (center) TC2, and (right) TC3, overlaid by the 850 -hPa horizontal wind vectors. The black $\times$ symbols indicate the vortex centers. By day 13 , the vortices in TC1 and TC3 become TCs, and the moisture (PW above $50 \mathrm{~mm}$ ) is wrapped inside the large-scale cyclonic vortices. However, the vortex in TC2 is drier and does not become a TC.

TC3 supports stronger convection and stronger vortex stretching (Figs. 8b-d). Figure 9 shows snapshots of the spatial organization of $\mathrm{PW}$, horizontal winds at $850 \mathrm{hPa}$, and the vortex locations of W2A on days 9, 11, and 13 . High PW ( $\geq 50 \mathrm{~mm}$, blue color scale) correlates well with precipitation. In all three simulations, the ITCZ initially supplies PW to the vortex.

In TC1 and TC3, on day 11 the PW and deep convective precipitation organize themselves around the vortex (Figs. 9d-f), and vortex stretching takes place (Fig. 8d). On day 13. there is weak horizontal wind shear between 200 and $850 \mathrm{hPa}$, in terms of both magnitude and direction; the positive vorticity extends to the upper troposphere (not shown). Figures 8 and 9 suggest that genesis is similar in the two simulations because the vortex spins up from the same large-scale flow patterns, but the resulting TC differs in intensity and size because of less predictable convective-scale processes.

In TC2, the vorticity $\eta_{850}$ is initially stronger than the rest, but the vortex interacts with a dry-air intrusion during the period when there is larger wind shear. The PW time series (Fig. 8c) and a PW map on day 9 (Fig. 9b) show the vortex has a dry center that cannot support adequate deep convection for vorticity stretching. Hence, the cyclonic vortex does not become a TC.

\section{c. Composites of the developing and nondeveloping waves}

We examined the evolution of all 17 developing waves (DWs) and 40 nondeveloping waves (NDWs) 
(a)

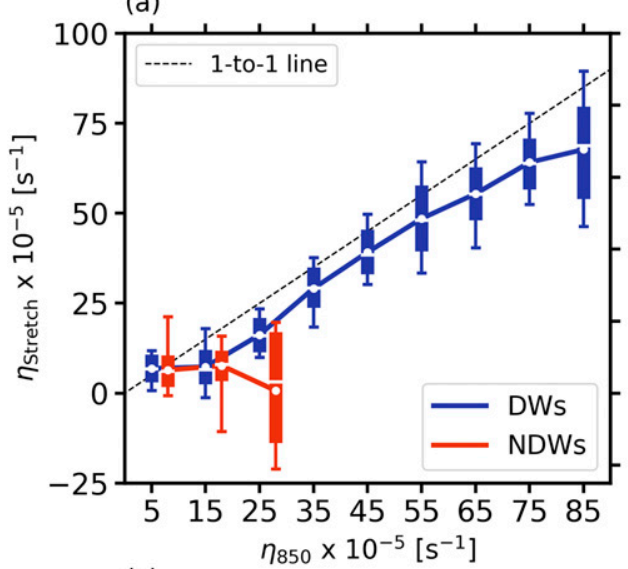

(c)

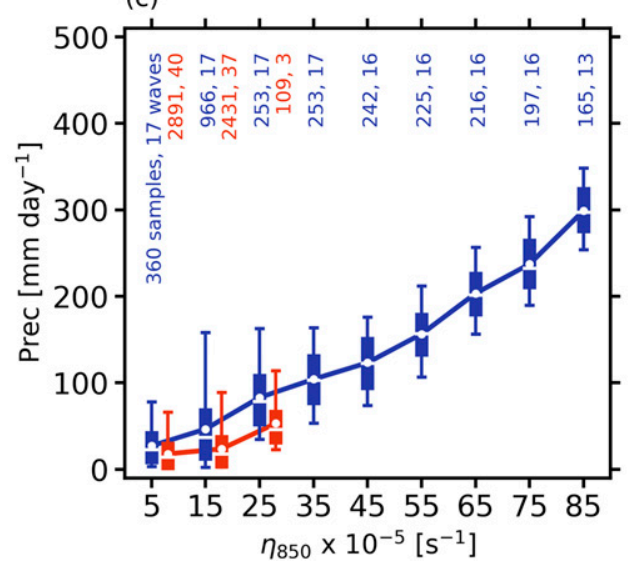

(b)

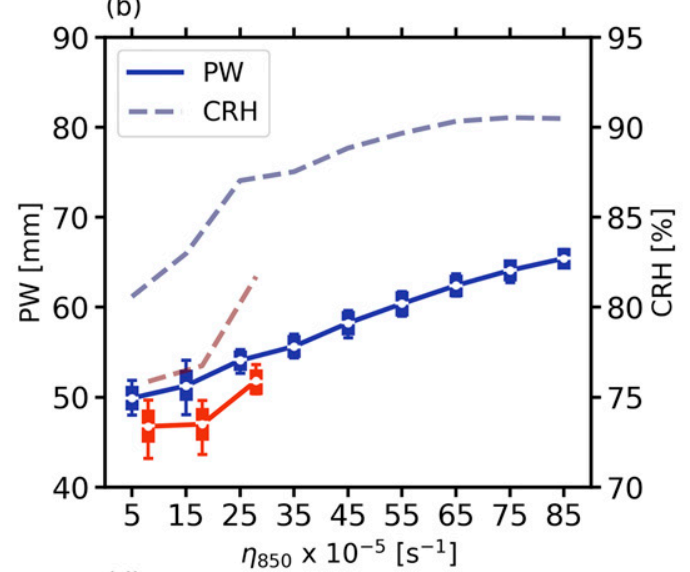

(d)

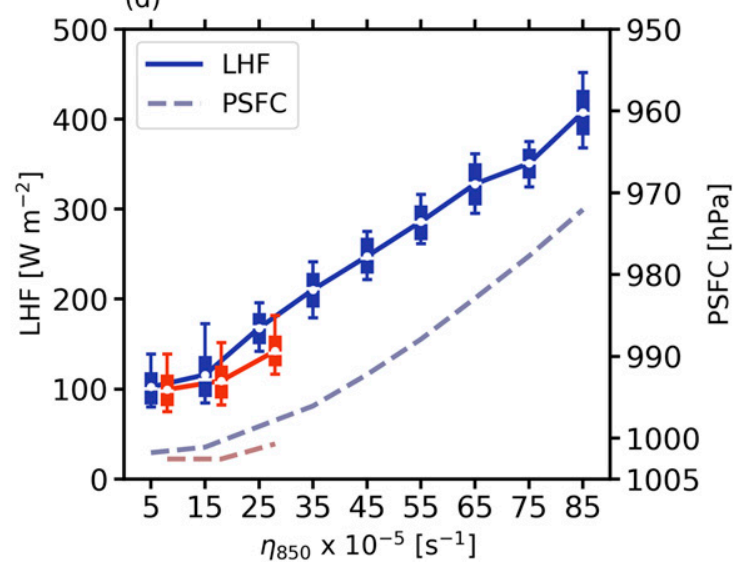

FIG. 10. Box-and-whisker plots of (a) $\eta_{\text {Stretch }}$ at $850 \mathrm{hPa}$, (b) PW, (c) Prec, and (d) surface LHF binned by $\eta_{850}$, averaged over $160 \times 160 \mathrm{~km}^{2}$ blocks following the vortices during the spinup period. For every $\eta_{850}$ bin, the minimum, 25th percentile, median (white lines), 75th percentile, maximum, and mean (dots) of the fields of interest are averaged within each wave, and then averaged again across all of the developing waves (DWs; blue) and nondeveloping waves (NDWs; red). There must be more than one sample within each $\eta_{850}$ bin for it to be counted. Numbers of the hourly samples and the wave disturbances are at the top of (c). A thin dashed line in (a) is a 1-to-1

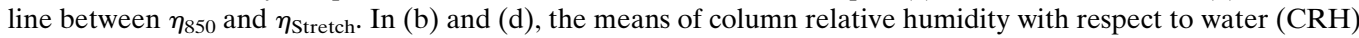
and PSFC from all $\eta_{850}$ bins are plotted as thick dashed lines.

from the three simulations. Almost all of the DW cases behave analogously to the just-discussed wave W2A. Cumulative vortex stretching $\eta_{\text {Stretch }}$ explains the changes in $\eta_{850}$ well, especially during the early phase of the TC spinup process, as previously discussed in section $5 \mathrm{~b}$. For the NDWs, $\eta_{\text {Stretch }}$ remains small and there is no strengthening of $\eta_{850}$.

Rather than show more cases, we compare in an average sense how different quantities change as the vortex evolves in developing and nondeveloping waves. We bin average the hourly time series data for all DWs by the $160 \times 160 \mathrm{~km}^{2}$ box-mean vortex-centered $\eta_{850}$, and similarly for the NDWs. Figure 10 shows boxand-whisker plots of selected quantities. Consistent with our prior discussion, for the DW composite, $\eta_{\text {Stretch }}$ explains all the increase of $\eta_{850}$, while for the NDW composite, there is insignificant $\eta_{\text {Stretch }}$ (Fig. 10a). However, NDWs often persist as cyclonic vortices with $\eta_{850}$ below $20 \times 10^{-5} \mathrm{~s}^{-1}$ for long periods. For a given absolute vorticity, DWs have higher PW and CRH (Fig. 10b), higher precipitation (Fig. 10c), higher surface LHF, and lower central pressure (Fig. 10d) than NDWs. Here, CRH is the ratio between PW and the saturated water vapor pressure, which is a better predictor of convective precipitation than PW itself (Bretherton et al. 2004). These factors promote convection in the vortex core and further vortex intensification by stretching. Furthermore, in DWs, all of these factors systematically increase with vorticity, supporting rapid development into a mature TC.

Figure 11 shows vortex-centered composite maps of PW and 850-hPa horizontal streamlines for DWs and 

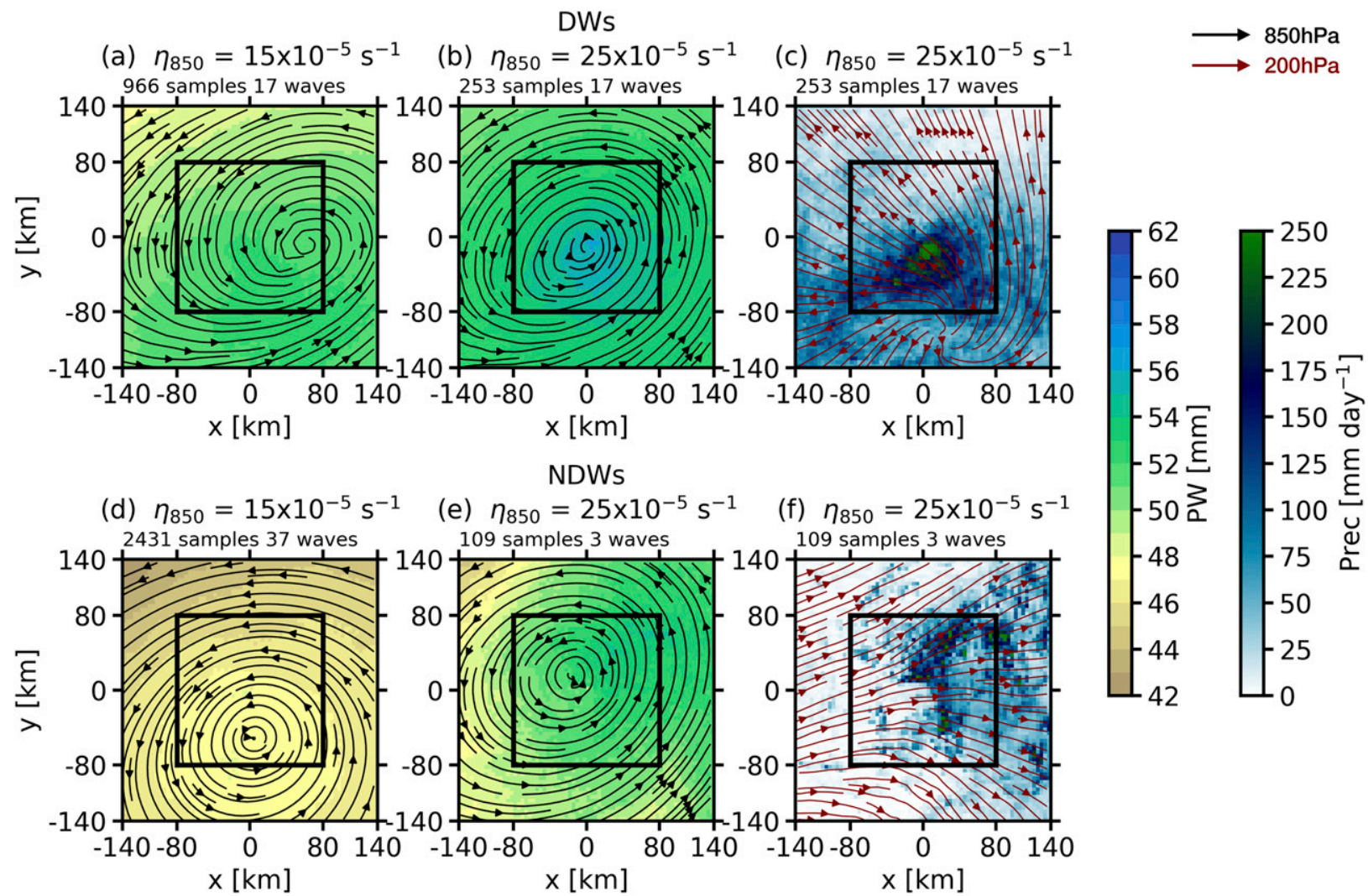

FIG. 11. Composites of hourly (left),(center) PW and (right) Prec binned by hourly averaged $160 \times 160 \mathrm{~km}^{2}$ blocks of $\eta_{850}$ following the vortices, with the same binning approach as in Fig. 10. The PW composites are from $15 \times 10^{-5}$ and $25 \times 10^{-5} \mathrm{~s}^{-1} \eta_{850}$ bins, and the Prec composites are from the $25 \times 10^{-5} \mathrm{~s}^{-1} \eta_{850}$ bin. Rows show the composites of (a)-(c) the developing waves (DWs) and (d)-(f) the nondeveloping waves (NDWs). The thin black (brown) lines with arrows overlaid on the PW (Prec) composites are the streamflows of horizontal winds at $850 \mathrm{hPa}(200 \mathrm{hPa})$. The thick black lines indicate the $160 \times 160 \mathrm{~km}^{2}$ domain.

NDWs for the second and third weakest $\eta_{850}$ bins, and of precipitation and 200-hPa horizontal streamlines for the stronger of these two bins, in which TCG is just starting for DWs. In the DWs, as the cyclonic circulation strengthens, it forms a protective pouch that traps moist, high PW air near the vortex center (Figs. 11a,b). The weak shear between the 200- and 850-hPa horizontal winds allows the cyclonic motion to extend throughout the entire troposphere (Figs. 11b,c). This helps sustain convection and results in a vortex-centered precipitation maximum that induces strong vortex stretching (Fig. 11c). The vortex centers of the NDWs are drier and near PW gradients rather than at a PW maximum (Figs. 11d,e). The upper-level winds do not form a circular motion but rather flow eastward through the vortex center. The shear breaks down the pouch and allows dry air intrusion from the west. The PW gradient and wind direction favor convective precipitation east of the vortex center (Fig. 11f) and therefore make the NDWs less favorable for vortex amplification by stretching.

\section{Discussion and conclusions}

Tropical cyclogenesis (TCG) is a multiscale process in which convective-scale activities interact with largescale circulations. We have used a near-global aquaplanet cloud-resolving model with a 4-km horizontal grid spacing to examine this process and its predictability. The SST distribution is zonally symmetric with a maximum at $15^{\circ} \mathrm{N}$, creating an off-equatorial ITCZ and a strong cross-equatorial Hadley circulation. In this configuration, resembling the east Pacific Ocean in September, TCs develop frequently at the north edge of the ITCZ at about $10^{\circ} \mathrm{N}$ from precursor vortices that form due to barotropic breakdown of lower tropospheric vorticity filaments that arise due to convective vortex stretching.

Three ensemble members differing only by small initial white-noise perturbations in the humidity field at a single model level near 3-km altitude are used to explore the predictability of TCG in this idealized setup. The precipitation decorrelates between the three simulations 
(a)
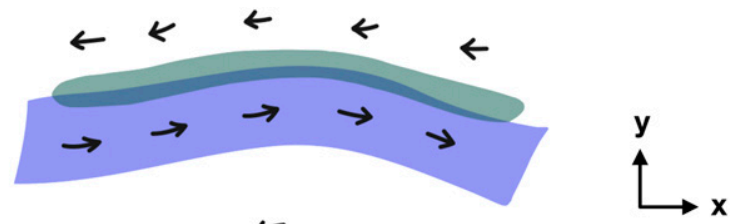

(b)
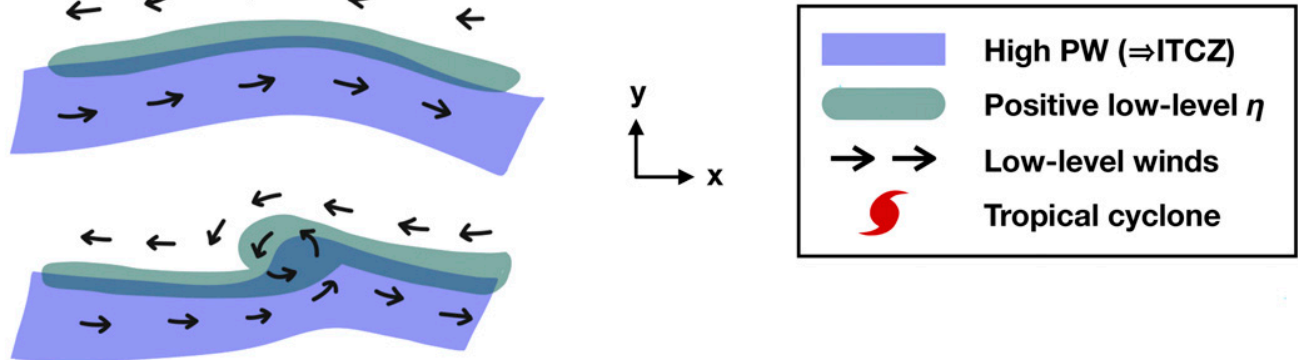

(c)

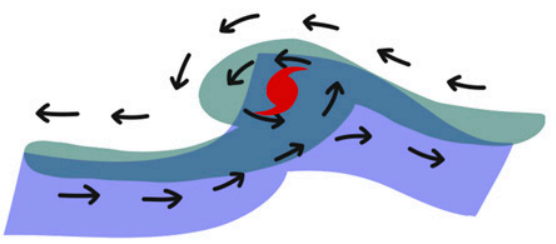

(d)

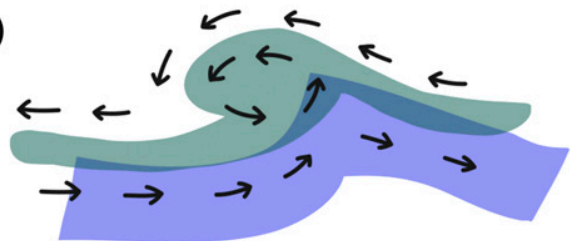

FIG. 12. Schematic of three stages of tropical cyclogenesis: (a) the formation of a low-level vorticity filament by stretching due to an elongated band of ITCZ convection, (b) the organization of a cyclonic vortex, and (c) the spinup of a tropical cyclone due to vorticity stretching. (d) The case in which there is insufficient humidity in the cyclonic vortex to support convective growth; therefore, vorticity stretching does not occur at the vortex center and the system does not become a TC. The light blue color indicates regions of high PW or the ITCZ. The teal color represents positive low-level absolute vorticity in the north edge of the ITCZ. The black arrows represent the directions of the low-level winds.

on the scale of a vortex in a few hours, so the details of vortex amplification via convectively induced stretching are unpredictable. However, large-scale precipitable water and wind anomalies are predictable up to 10 days. This leads to similar predictability time scales of preferred locations for precursor vortex formation and its interaction with moist tongues that can help organize convective precipitation and ultimately promote genesis. This large-scale control makes the location and timing of TCG surprisingly predictable despite the small-scale stochasticity of moist convection.

Figure 12 is a schematic diagram demonstrating interactions between the ITCZ, humidity, horizontal flows, and convection that lead to TCG. These processes involve both larger, more predictable and smaller, less predictable scales. Convective vortex stretching in the high-vorticity inflow into the north side of the ITCZ creates cyclonic vorticity filaments in the lower troposphere that undergo barotropic instability (Fig. 12a) and roll up into cyclonic vortices (Fig. 12b). Convective latent heating and low-level vortex stretching aid the spinup of the vortices into TCs. The convection is sensitive to the lower to midtropospheric humidity and wind shear; these affect which vortices develop into TCs (Fig. 12c) and which do not (Fig. 12d).

Global cloud-resolving models (GCRMs) are powerful tools for studying TCG since they do not rely on uncertain cumulus parameterizations, and should become a central tool for understanding TC formation and evolution.
A few follow-on questions that could be addressed by future idealized GCRM predictability studies are as follows: How important to the predictability of TCG are initial humidity perturbations inside the cyclonic vortex versus far from the vortex? Are small-scale or largescale humidity perturbations more important? Also, in our study, the seed vortices for TCs developed through an internal instability of the ITCZ. A GCRM with realistic geography and SST can represent real-world processes that create such vortices, such as African easterly waves and monsoon troughs, and those vortex-forming processes may affect the regional predictability of TCG.

Acknowledgments. The model outputs used to generate the main analyses and figures of developing tropical cyclones in this paper are archived in the University of Washington ResearchWorks Archive http://hdl.handle.net/1773/44981. Additional model outputs are available upon e-mail request to the first author. The research projects were made possible by funding from Department of Energy Grant DE-SC0012451, the National Science Foundation Science, and Technology Center for Multi-Scale Modeling of Atmospheric Processes (CMMAP) under Grant ATM-0425247, the National Science Foundation Grant AGS-1912130, and by a scholarship from Thailand's Ministry of Higher Education, Science, Research and Innovation. Computational resources were provided by the Extreme Science and Engineering Discovery Environment (XSEDE) (Grant OCI-1053575). The authors 
thank Shuyi Chen, Dargan Frierson, and Dale Durran for helpful comments.

\section{APPENDIX}

\section{Algorithm for Tracking TCs in NGAqua}

The algorithm developed for tracking the easterly waves and TCs in NGAqua simulations is described below. Because the vorticity field is noisy and the cyclonic vortices in NGAqua are parts of mesoscale wave disturbances, we consider the instantaneous, hourly $850-\mathrm{hPa}$ relative vorticity that is coarse averaged to 80-km resolution:

$$
\zeta_{850,80 \mathrm{~km}}=\left(\frac{\partial v}{\partial x}-\frac{\partial u}{\partial y}\right)_{80 \mathrm{~km}},
$$

where $u$ and $v$ are zonal and meridional winds at $850 \mathrm{hPa}$. The vorticity is computed using center-differencing of $u$ and $v$ at $80-\mathrm{km}$ grid spacing. Since the cyclonic vortices in NGAqua organize from vorticity filaments, where there is strong meridional shear of zonal winds $\left(-u_{y, 80 \mathrm{~km}}\right)$ due to the ITCZ mean flows and the trade winds, we first ensure that the zonal shear of meridional winds $\left(v_{x, 80 \mathrm{~km}}\right)$ contributes equally to the relative vorticity. Hence, the grid columns in NGAqua are considered cyclonic vortices if the following conditions are met:

$$
\begin{gathered}
\mathrm{SST} \geq 25^{\circ} \mathrm{C}, \\
\left(\frac{\partial v}{\partial x}\right)_{80 \mathrm{~km}} \geq 1.5 \times 10^{-5} \mathrm{~s}^{-1}, \\
-\left(\frac{\partial u}{\partial y}\right)_{80 \mathrm{~km}} \geq 1.5 \times 10^{-5} \mathrm{~s}^{-1} .
\end{gathered}
$$

Otherwise the grid columns are discarded after each step. Equations (A3) and (A4) imply that the cyclonic vortices have $\zeta_{850,80 \mathrm{~km}} \geq 3.0 \times 10^{-5} \mathrm{~s}^{-1}$.

Then, we use the density-based spatial clustering of applications with noise or DBSCAN (Ester et al. 1996) to locate the vortex clusters; the algorithm discards noises and effectively groups the adjacent grid points. For each cluster, the point with minimum PSFC below the cluster's one standard deviation is considered the vortex center. If such grid point cannot be found, then the point with highest $\zeta_{850,80 \mathrm{~km}}$ weight is considered the vortex centers.

After that, DBSCAN is used to group the grid points from each time step into tracks of cyclonic vortices. For each track, at every time step there is only one $80-\mathrm{km}$ grid point that is considered the vortex center. We then extrapolate the grid locations at $80-\mathrm{km}$ resolution back to 4-km resolution, which is the original resolution of NGAqua.

The easterly wave and TC tracks obtained at this step are noisy time series and need further smoothing. Following the tracks, we pick a time window depending on the track lengths and center average the latitudes and longitudes of the vortex centers: if the track length is longer than $60 \mathrm{~h}$, the window width $\left(N_{w}\right)$ is $12 \mathrm{~h}$; if the track length is between 30 and $60 \mathrm{~h}, N_{w}$ is $6 \mathrm{~h}$; otherwise, $N_{w}$ is $3 \mathrm{~h}$. For the beginning and the end of each track, we reduce $N_{w}$ such that the vortex centers at the first and last time steps of the tracks remain unchanged during the smoothing process. At the end, we obtain hourly time series of the track locations. We ensure that the vortex center is the point with minimum PSFC inside a circle of $80-\mathrm{km}$ radius at every time step.

Finally, we classify the tracks into pre-TC vortices versus TCs. If at any point the minimum PSFC deepens below $980 \mathrm{hPa}$, the track is considered a TC. Otherwise, the track remains a cyclonic vortex. An exception is when the $850-\mathrm{hPa}$ absolute vorticity $\left(\eta_{850}=\zeta_{850}+f\right)$ averaged over a $160 \times 160 \mathrm{~km}^{2}$ block following the vortex increases by $10 \times 10^{-5} \mathrm{~s}^{-1}$ within $48 \mathrm{~h}$, then after that time step the cyclonic vortex becomes a TC.

\section{REFERENCES}

Bister, M., and K. A. Emanuel, 1997: The genesis of Hurricane Guillermo: TEXMEX analyses and a modeling study. Mon. Wea. Rev., 125, 2662-2682, https://doi.org/10.1175/15200493(1997)125<2662:TGOHGT>2.0.CO;2.

Bretherton, C. S., and M. F. Khairoutdinov, 2015: Convective selfaggregation feedbacks in near-global cloud-resolving simulations of an aquaplanet. J. Adv. Model. Earth Syst., 7, 1-23, https://doi.org/10.1002/2015MS000499.

— M. E. Peters, and L. E. Back, 2004: Relationships between water vapor path and precipitation over the tropical oceans. J. Climate, 17, 1517-1528, https://doi.org/10.1175/ 1520-0442(2004)017<1517:RBWVPA>2.0.CO;2.

—, P. N. Blossey, and M. Khairoutdinov, 2005: An energybalance analysis of deep convective self-aggregation above uniform SST. J. Atmos. Sci., 62, 4273-4292, https://doi.org/ 10.1175/JAS3614.1.

Chen, S. S., and W. M. Frank, 1993: A numerical study of the genesis of extratropical convective mesovortices. Part I: Evolution and dynamics. J. Atmos. Sci., 50, 2401-2426, https://doi.org/10.1175/15200469(1993)050<2401:ANSOTG $>2.0 . C O ; 2$.

Collins, W. D., and Coauthors, 2006: The formulation and atmospheric simulation of the Community Atmosphere Model version 3 (CAM3). J. Climate, 19, 2144-2161, https://doi.org/ 10.1175/JCLI3760.1.

Davis, C. A., 2015: The formation of moist vortices and tropical cyclones in idealized simulations. J. Atmos. Sci., 72, 34993516, https://doi.org/10.1175/JAS-D-15-0027.1.

de Szoeke, S. P., S.-P. Xie, T. Miyama, K. J. Richards, and R. J. O. Small, 2007: What maintains the SST front north of the eastern 
Pacific equatorial cold tongue? J. Climate, 20, 2500-2514, https://doi.org/10.1175/JCLI4173.1.

Dunkerton, T. J., M. T. Montgomery, and Z. Wang, 2009: Tropical cyclogenesis in a tropical wave critical layer: Easterly waves. Atmos. Chem. Phys., 9, 5587-5646, https://doi.org/10.5194/ acp-9-5587-2009.

Emanuel, K., 2018: 100 years of progress in tropical cyclone research. A Century of Progress in Atmospheric and Related Sciences: Celebrating the American Meteorological Society Centennial, Meteor. Monogr., No. 59, Amer. Meteor. Soc., 15.1-15.68, https://doi.org/10.1175/AMSMONOGRAPHS-D18-0016.1.

Ester, M., H.-P. Kriegel, J. Sander, and X. Xu, 1996: A densitybased algorithm for discovering clusters in large spatial databases with noise. Proc. Second Int. Conf. on Knowledge Discovery and Data Mining, Portland, OR, Association for the Advancement of Artificial Intelligence, 226-231, http:// dl.acm.org/citation.cfm?id $=3001460.3001507$.

Ferreira, R. N., and W. H. Schubert, 1997: Barotropic aspects of ITCZ breakdown. J. Atmos. Sci., 54, 261-285, https://doi.org/ 10.1175/1520-0469(1997)054<0261:BAOIB > 2.0.CO;2.

Frank, W. M., and P. E. Roundy, 2006: The role of tropical waves in tropical cyclogenesis. Mon. Wea. Rev., 134, 2397-2417, https:// doi.org/10.1175/MWR3204.1.

Gjorgjievska, S., and D. J. Raymond, 2014: Interaction between dynamics and thermodynamics during tropical cyclogenesis. Atmos. Chem. Phys., 14, 3065-3082, https://doi.org/10.5194/ acp-14-3065-2014.

Gray, W. M., 1968: Global view of the origin of tropical disturbances and storms. Mon. Wea. Rev., 96, 669-700, https://doi.org/10.1175/ 1520-0493(1968)096<0669:GVOTOO>2.0.CO;2.

Haynes, P. H., and M. E. McIntyre, 1987: On the evolution of vorticity and potential vorticity in the presence of diabatic heating and frictional or other forces. J. Atmos. Sci., 44, 828-841, https://doi.org/10.1175/1520-0469(1987)044<0828: OTEOVA $>2.0 . \mathrm{CO} ; 2$.

Houze, R. A., Jr., 2010: Clouds in tropical cyclones. Mon. Wea. Rev., 138, 293-344, https://doi.org/10.1175/2009MWR2989.1.

Kerns, B. W., and S. S. Chen, 2015: Subsidence warming as an underappreciated ingredient in tropical cyclogenesis. Part I: Aircraft observations. J. Atmos. Sci., 72, 4237-4260, https:// doi.org/10.1175/JAS-D-14-0366.1.

Khairoutdinov, M. F., and D. Randall, 2003: Cloud resolving modeling of the ARM summer 1997 IOP: Model formulation, results, uncertainties, and sensitivities. J. Atmos. Sci., 60, 607-625, https://doi.org/10.1175/1520-0469(2003)060<0607: CRMOTA $>2.0 . \mathrm{CO} ; 2$.

Leppert, K. D., D. J. Cecil, and W. A. Petersen, 2013: Relation between tropical easterly waves, convection, and tropical cyclogenesis: A Lagrangian perspective. Mon. Wea. Rev., 141, 2649-2668, https://doi.org/10.1175/MWR-D-12-00217.1.

Muller, C. J., and D. M. Romps, 2018: Acceleration of tropical cyclogenesis by self-aggregation feedbacks. Proc. Natl. Acad. Sci. USA, 115, 2930-2935, https://doi.org/10.1073/ pnas.1719967115.
Narenpitak, P., C. S. Bretherton, and M. F. Khairoutdinov, 2017: Cloud and circulation feedbacks in a near-global aquaplanet cloud-resolving model. J. Adv. Model. Earth Syst., 9, 10691090, https://doi.org/10.1002/2016MS000872.

Neale, R. B., and B. J. Hoskins, 2000: A standard test for AGCMs including their physical parametrizations: I: The proposal. Atmos. Sci. Lett., 1, 101-107, https://doi.org/ 10.1006/asle.2000.0022.

Nolan, D. S., 2011: Evaluating environmental favorableness for tropical cyclone development with the method of pointdownscaling. J. Adv. Model. Earth Syst., 3, M08001, https:// doi.org/10.1029/2011MS000063.

Raymond, D. J., and L. C. Carrillo, 2011: The vorticity budget of developing Typhoon Nuri. Atmos. Chem. Phys., 11, 147-163, https://doi.org/10.5194/acp-11-147-2011.

- Z Z. Fuchs, S. Gjorgjievska, and S. Sessions, 2015: Balanced dynamics and convection in the tropical troposphere. J. Adv. Model. Earth Syst., 7, 1093-1116, https://doi.org/ 10.1002/2015MS000467.

Ritchie, E., and G. Holland, 1999: Large-scale patterns associated with tropical cyclogenesis in the western Pacific. Mon. Wea. Rev., 127, 2027-2043, https://doi.org/10.1175/1520-0493(1999) 127<2027:LSPAWT>2.0.CO;2.

Rushley, S. S., D. Kim, C. S. Bretherton, and M.-S. Ahn, 2018: Reexamining the nonlinear moisture-precipitation relationship over the tropical oceans. Geophys. Res. Lett., 45, 11331140, https://doi.org/10.1002/2017GL076296.

Schreck, C. J., J. Molinari, and A. Aiyyer, 2012: A global view of equatorial waves and tropical cyclogenesis. Mon. Wea. Rev., 140, 774-788, https://doi.org/10.1175/MWR-D-11-00110.1.

Smolarkiewicz, P. K., and W. W. Grabowski, 1990: The multidimensional positive definite advection transport algorithm: Nonoscillatory option. J. Comput. Phys., 86, 355-375, https:// doi.org/10.1016/0021-9991(90)90105-A.

Tyner, B., and A. Aiyyer, 2012: Evolution of African easterly waves in potential vorticity fields. Mon. Wea. Rev., 140, 36343652, https://doi.org/10.1175/MWR-D-11-00170.1.

Vecchi, G. A., and Coauthors, 2019: Tropical cyclone sensitivities to $\mathrm{CO}_{2}$ doubling: Roles of atmospheric resolution, synoptic variability and background climate changes. Climate Dyn., 53, 5999-6033, https://doi.org/10.1007/s00382-019-04913-y.

Wang, C., and G. Magnusdottir, 2005: ITCZ breakdown in threedimensional flows. J. Atmos. Sci., 62, 1497-1512, https:// doi.org/10.1175/JAS3409.1.

Wing, A. A., S. J. Camargo, and A. H. Sobel, 2016: Role of radiative-convective feedbacks in spontaneous tropical cyclogenesis in idealized numerical simulations. J. Atmos. Sci., 73, 2633-2642, https://doi.org/10.1175/JAS-D-15-0380.1.

Wu, L., and J. Duan, 2015: Extended simulation of tropical cyclone formation in the western North Pacific monsoon trough. J. Atmos. Sci., 72, 4469-4485, https://doi.org/10.1175/JAS-D14-0375.1.

Zhang, F., and D. Tao, 2013: Effects of vertical wind shear on the predictability of tropical cyclones. J. Atmos. Sci., 70, 975-983, https://doi.org/10.1175/JAS-D-12-0133.1. 